NATIONAL RESEARCH, DEVELOPMENT AND INNOVATION OFFICE HUNGARY

\title{
RESEARCH \\ INFRASTRUCTURES \\ FOR EXCELLENCE IN \\ HUNGARY
}


A foreword by
István Szabó PhD,

vice president for science and
international affairs, NRDIO

The competitiveness of any country greatly depends on how efficiently it can use opportunities unearthed by scientific and technological innovation Along with our internationally acclaimed educational and research institutions, domestic research infrastructures are key in this multifaceted struggle for excellence. Not only these research infrastructures (RI's) provide the essential foundation for fundamental and exploratory

research, but they also exert a significant impact both on a social and an economical level. Having focused on Rl's as a researcher

has taught me that the more access to world-class infrastructures a country has the better, as it can cope with challenges on the long run. In this respect I can proudly say that Hungary has a lot to offer.

Hungary's participation in internationally outstanding research infrastructures creates a number of opportunities for domestic researchers to shape and enhance their professional development, supports their affiliation with international research networks and encourages the formation of multidisciplinary collaborations. In order to widen and enhance co-operation on all levels, the National Research, Development and Innovation Office (NRDIO) have joined a number of interna recent years thus providing direct access for local professionals in research and development to the circulation of international science and innovation.

Research infrastructures are key in the realization of $\mathrm{R}+\mathrm{D}+\mathrm{l}$ co-operations within the ever-widening network of, among many others, higher education institutions, academic research facilities, state-run nonprofit research organizations, centres of research and technology and businesses of all sizes. With the correct strategy, the interoperability of academic- and industry players will become the propelling force underlying the country's economic growth.

With the simplest approach, the primary role of research infrastructures is the continuous and efficient production of knowledge, so that excellence, wherever possible, is achieved, making our lives better. However, all this requires ever-expanding co-operation with transborder research infrastructures, intensive networking between the various research facilities and the continuous development of the infrastructures. Hereby I invite all international researchers to take a look or two at the main research infrastructures in Hungary and find your next stop in $\mathrm{R}+\mathrm{D}+\mathrm{l}$. Because like I said above, in research and development our country has a lot to offer.
RESEARCH AND DEVELOPMENT IN HUNGARY: WE HAVE A LOT TO OFFER

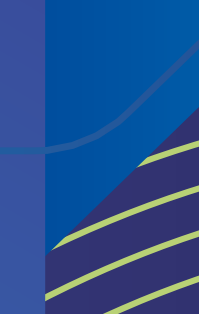




\section{TABLE OF CONTENTS}

Click to jump to any section

(1) INTRODUCTION

(2) HUNGARY'S MEMBERSHIPS IN EUROPEAN RESEARCH INFRASTRUCTURES

(3) RESEARCH INFRASTRUCTURES OVERVIEW

(4) RESEARCH INFRASTRUCTURES IN HUNGARY

\section{ENERGY}

eNVIRONMENT

I) HEALTH \&FOOD

PHYSICAL SCIENCES \& ENGINEERING

g9 SOCIAL \& CULTURAL INNOVATION

\# DATA, COMPUTING AND DIGITAL RIS 


\section{INTRODUCTION}

Hungary, through the National Research, Development and Innovation Office (NRDI Office) has joined several international research infrastructures (see https:// nkfih.gov.hu/nemzet-kutatasi-infrastruktura-utiterv) in recent years to enhance our

international cooperation. The NRDI Office spends more than 10 million EUR annually on membership fees associated with our participation in international research infrastructures and organizations. While improving excellence in science is our main goal, an equally important aspect and aim of our contribution is to enhance the economic advantages of our membership by increasing the share of in-kind contributions.

Hungary participates in 16 projects and landmarks included in the latest Roadmap 2018 of the European Strategy Forum on Research Infrastructures (ESFRI). In addition, Hungary participates in several non-ESFRI related research infrastructures (e.g. CERN, EMBL, ICGEB, etc.) where Hungarian researchers can also benefit from our membership. Among the ESFRI RIs, the Extreme Light Infrastructure (ELI) project has a significant importance for us, since the ELI-Attosecond Light Pulse Source (ELI-ALPS) next generation laser facility has been built in Hungary and it is an integral part of the pan-European RI landscape. The Extreme Light Infrastructure is the first infrastructure in the world capable of investigating the interactions between light and matter with the highest intensity, in the so-called ultra-relativistic range. It will open a doorway into new territories of science and will have a considerable impact on numerous fields of material science, medicine and environment protection.

It is an important goal for us to enable Hungarian researchers to get into the stream of the research provided by the international research infrastructures as efficiently as possible, therefore in 2019 we have introduced a new call for proposal, under which researchers can apply for support to their travel and stay at the host institution and also the dissemination costs of their research results can be covered.

In connection with the update of the ESFRI Roadmap 2018 planned for 2021 by the ESFRI Forum, we assessed in a nationwide survey which fields the Hungarian researcher community would have an interest to join the ESFRI Roadmap 2018 Projects and Landmarks. As a result of the survey, Hungary is expected to join more international research infrastructures effective from 2021, which we include in our present summary 



\section{o HEALTH \& FOOD}

RI short

name

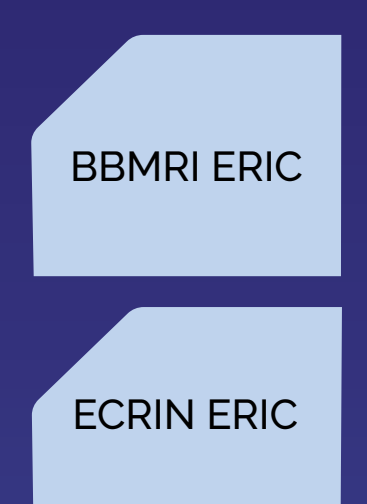

ELIXIR

EMBL

ERINHA

\section{ICGEB}

\section{RI name}

Biobanking and BioMolecular Resources Research Infrastructure - European Research Infrastructure Consortium

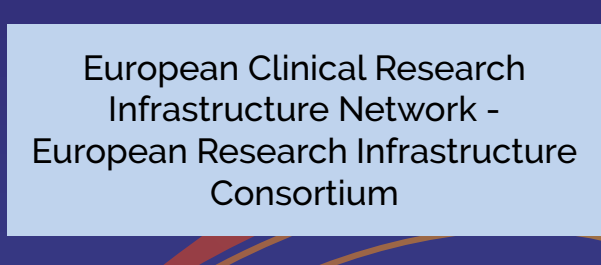

European Life-sciences Infrastructure for Biological Information

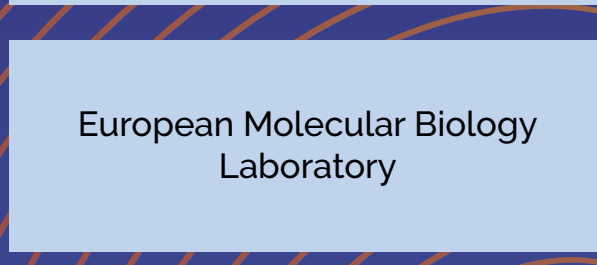

European Research Infrastructure on Highly Pathogenic Agents

European Research Infrastructure for Imaging Technologies in Biological and Biomedical Sciences - European Research Infrastructure Consortium

International Centre for Genetic Engineering and Biotechnology
ESFRI

Landmark/

Project

2021

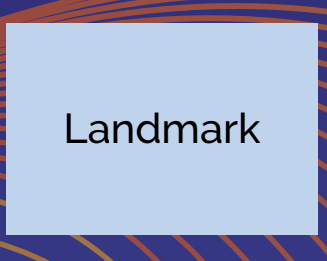

Landmark

2016

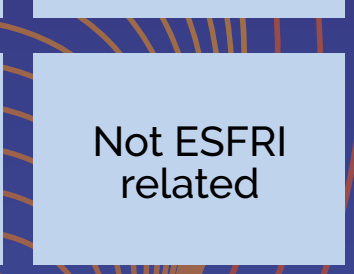

Landmark

2018

2017

2017
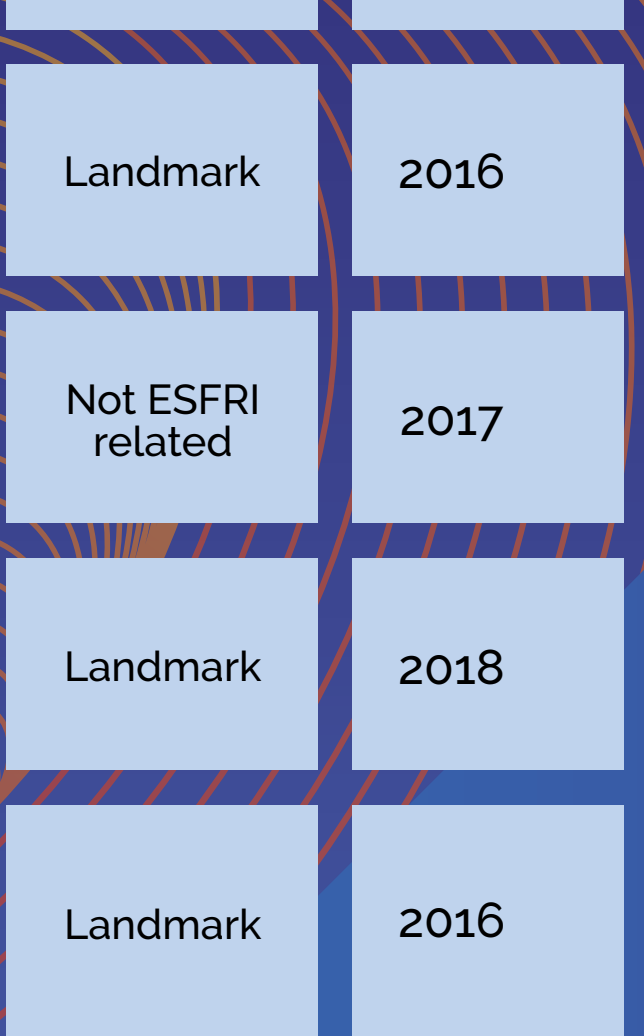

Not ESFRI arelated
Landmark
Hungary's membership in European research infrastructures
Start of

participation

(year)

\section{Brief description}

The biobanking research infrastructure brings together all the main players from the biobanking field - researchers, biobankers, industry, and patients - to boost biomedical research. The ultimate goal is to make new treatments possible.

Supports the creation of a high quality, transparent, multinational system of clinical trials by mitigating the drawbacks of the fragmented clinical trial environment and poor interoperability.

The European initiative connects and integrates into a single infrastructure the majo bioinformatics resources of national centres, hubs and service providers. It supports many fields of life sciences, including research in the field of agriculture and medicine.

One of the leading European laboratories in life sciences. It has 80 independent member research institutions covering the full spectrum of molecular biology from the molecule to the organism, including the fields of system biology and bioinformatics.

Infrastructure network focusing on the examination and analysis of the properties and spreading of microscopic germs infecting animals and humans, and the public health, social and economic consequences of contagious diseases.

Provides access to a wide range of state-of-the-art technologies in biological and clinical imaging. It aims to connect the specialised, geographically fragmented national hubs to reach all European researchers in the member states.

Every year, the ICGEB announces an open call for cooperative biotechnology research projects, for $\mathrm{PhD}$ and Postdoctoral fellowship applications, and for proposals relating to the organisation of conferences and training courses. 


\section{PHYSICAL SCIENCES \& ENGINEERING}

Hungary's membership in European research infrastructures

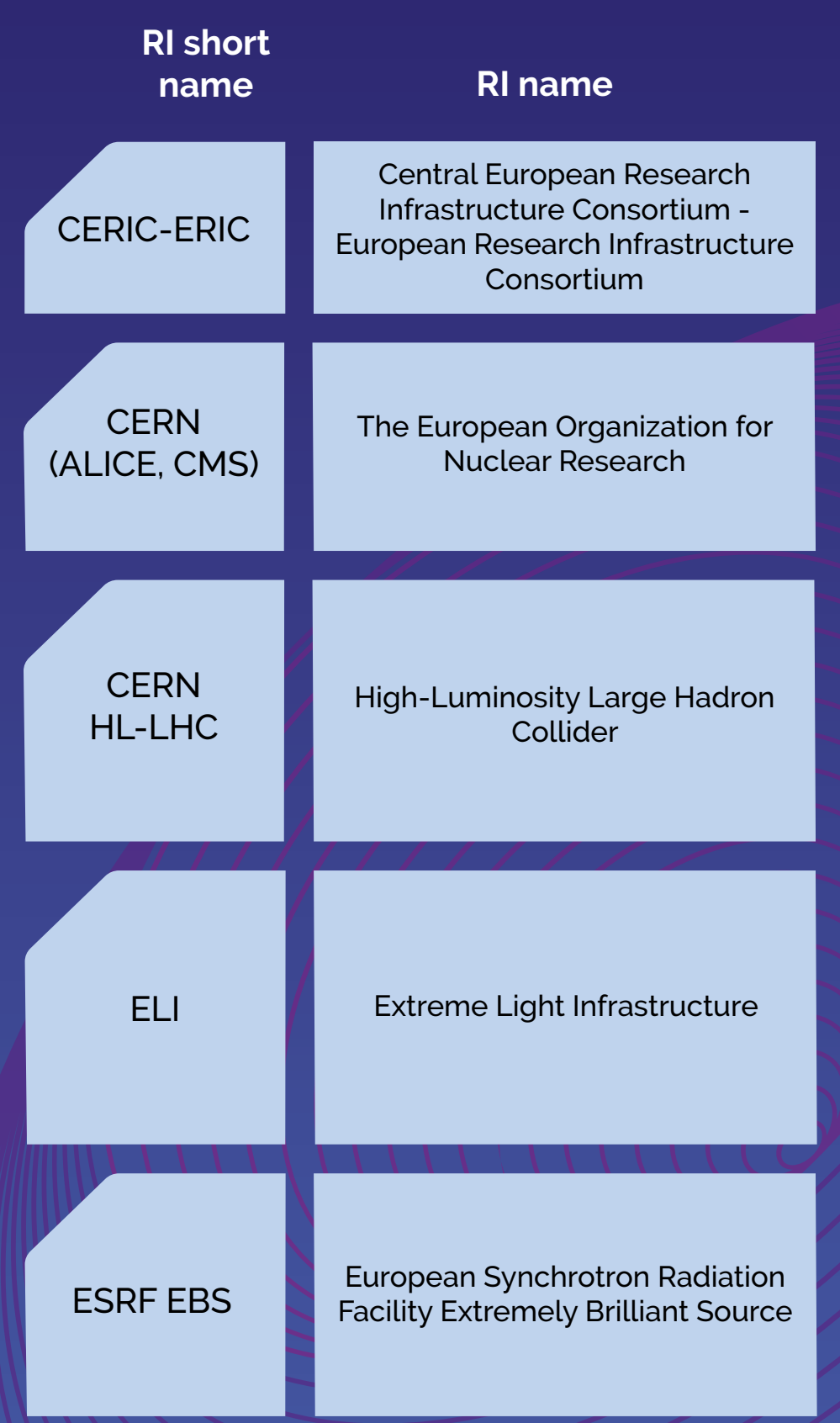

ESFRI

Landmark/

Project

\section{Not ESFRI \\ related}
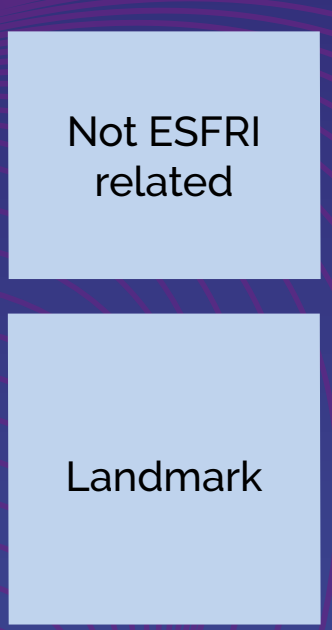

Landmark

2013

2014 articipation (year)

2017

1992
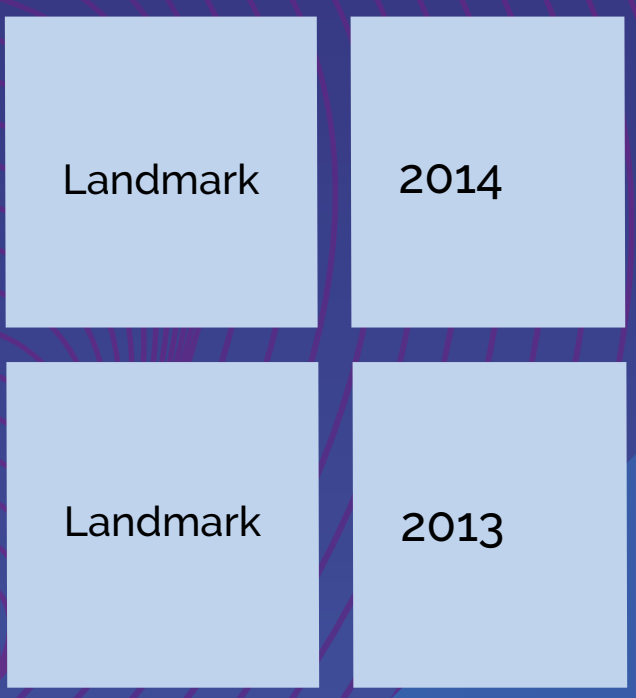

Landmark

\section{Brief description}

The multidisciplinary research infrastructure integrates research projects in 7 European countries in the fields of materials science and nanotechnology at market price. The main focus of the consortium is open access (researcher exchange). Access is free of charge for commercial and industrial research projects.

The European Organization for Nuclear Research (CERN) is one of the most prestigious research centres in the world. Its main mission is basic research in particle physics with an aim to better understand the properties of basic interactions and the relationships of the universe. It designs, builds and operates complex particle accelerator equipment.

The Large Hadron Collider (LHC) operated by CERN is going to be upgraded to increased intensity between 2019 and 2026. The detectors are also being upgraded: this work has already started in 2018. Of the four large detectors of LHC, Hungary participates in the experiments of ALICE and CMS. The CMS (and Atlas) project contributed to the discovery of the Higgs boson. The ALICE project recreates the primary matter through heavy-ion collisions.

The primary mission of the ELI Attosecond Light Pulse Source (ELI-ALPS) research infrastructure in Szeged is to provide access to a wide range of ultra-short light pulses sources for various user groups of the international scientific community. Another main element in the facility's mission is to promote the scientific and technological developments necessary for delivering lasers with high peak intensity and high average performance.

The world's leading X-ray source. A state-of-the-art equipment enabling the atomic and nano-scale examination of matter in various fields of science: solid-state physics, medicine, pharmacy, earth sciences, environmental science and archaeology. There are many synchrotron sources across the world, but the ESRF is unique in terms of test beam parameters and the number of measurement channels. 

\& ENGINEERING

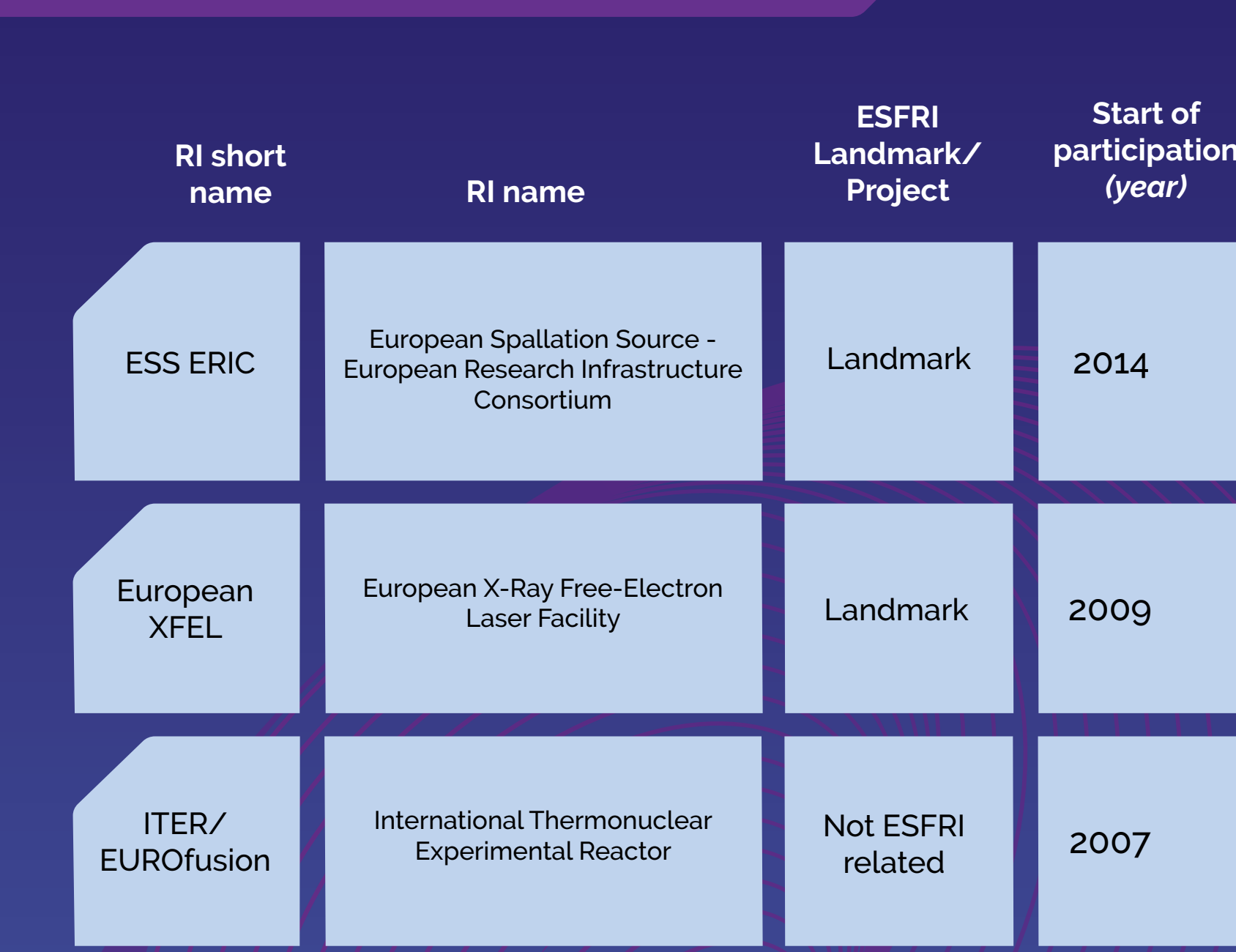

ESS is the world's first so-called long-pulse spallation neutron source. Its mission is to build and operate a world leading facility for neutron research. The world's highest intensity neutron source enables the examination of systems which has never been possible due to the small size of the sample or the small intensity of the examined signal. The equipment gives a great boost to domestic research in physics, chemistry and materials science.

This facility is unique in Europe and is used for ultra-short (27 thousands/sec) and very bright $\mathrm{X}$-ray experiments. With such parameters the facility opens up entirely new opportunities for scientific and industrial research. Researchers can map viruses at the atomic level, understand the molecular structure of cells, create 3D images of the nano-world, etc.

The ITER aims to demonstrate that nuclear fusion can be used on Earth for energy purposes and testing technological solutions. ITER is considered unavoidable by competent researchers on the way to creating a fusion energy. Fusion related research and development is performed by EUROfusion program which integrates all member states' research projects in this field. 


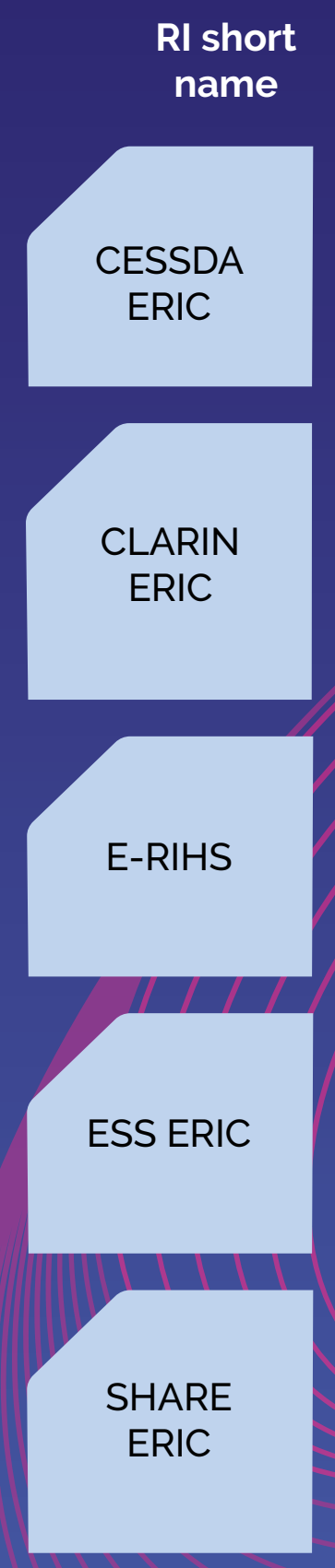

ESFRI

Landmark/

Project

Landmark

Social Science Data Archives -

European Research Infrastructure Consortium

Common Language Resources and Technology Infrastructure European Research Infrastructure Consortium

Landmark

2016 articipation (year)

2017

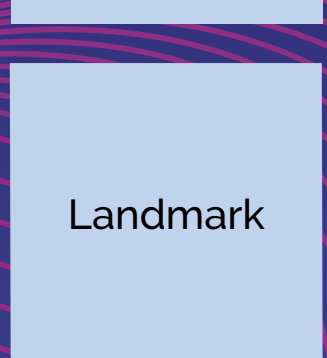

European Research Infrastructure for Heritage Science

2021

European Social Survey European Research Infrastructure Consortium

2016

Survey of Health, Ageing and Retirement in Europe
PROJECT

Landmark
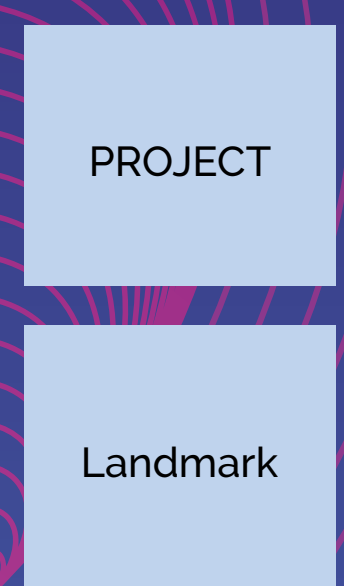

Landmark

\section{Brief description}

The only virtual research infrastructures which provides a single interface to the social scientific databases of all EU member states and associated members. It is essential for the access and use of comparative social scientific databases for administrative and scientific purposes.

A research infrastructure that provides advanced digital language resources and tools- primarily for scholars and social scientists. The CLARIN - ERIC was created by the merger of three ESFRI language technology initiatives. One of the founding parties was the Research Institute for Linguistics of the Hungarian Academy of Sciences, which still plays and played a leading role in the preparatory project as well.

Supports research on heritage interpretation, preservation, documentation and management, in order to deliver integrated access to expertise, data and technologies through a standardized approach, and to integrate world-leading European facilities into an organisation.

ESS provides biannual comparative data about the demographic and social conditions of European societies, the changes in political and public preferences of citizens, and changes in social attitudes and action-guiding values. Data may significantly contribute to understanding changes in social behaviour taking place in Europe.

SHARE is a multidisciplinary panel database of information on the health, use of the healthcare system, financial status and income, socio-economic background and social and family networks of more than 30,000 individuals aged 50 or older. The aim is to build up a database that allows for high-quality, fact-based decisions on issues related to aging. 


\section{\# DATA, COMPUTING AND Digital RIs}

\section{Hungary's membership in European}

research infrastructures

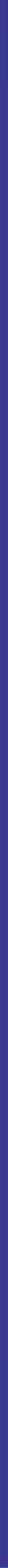




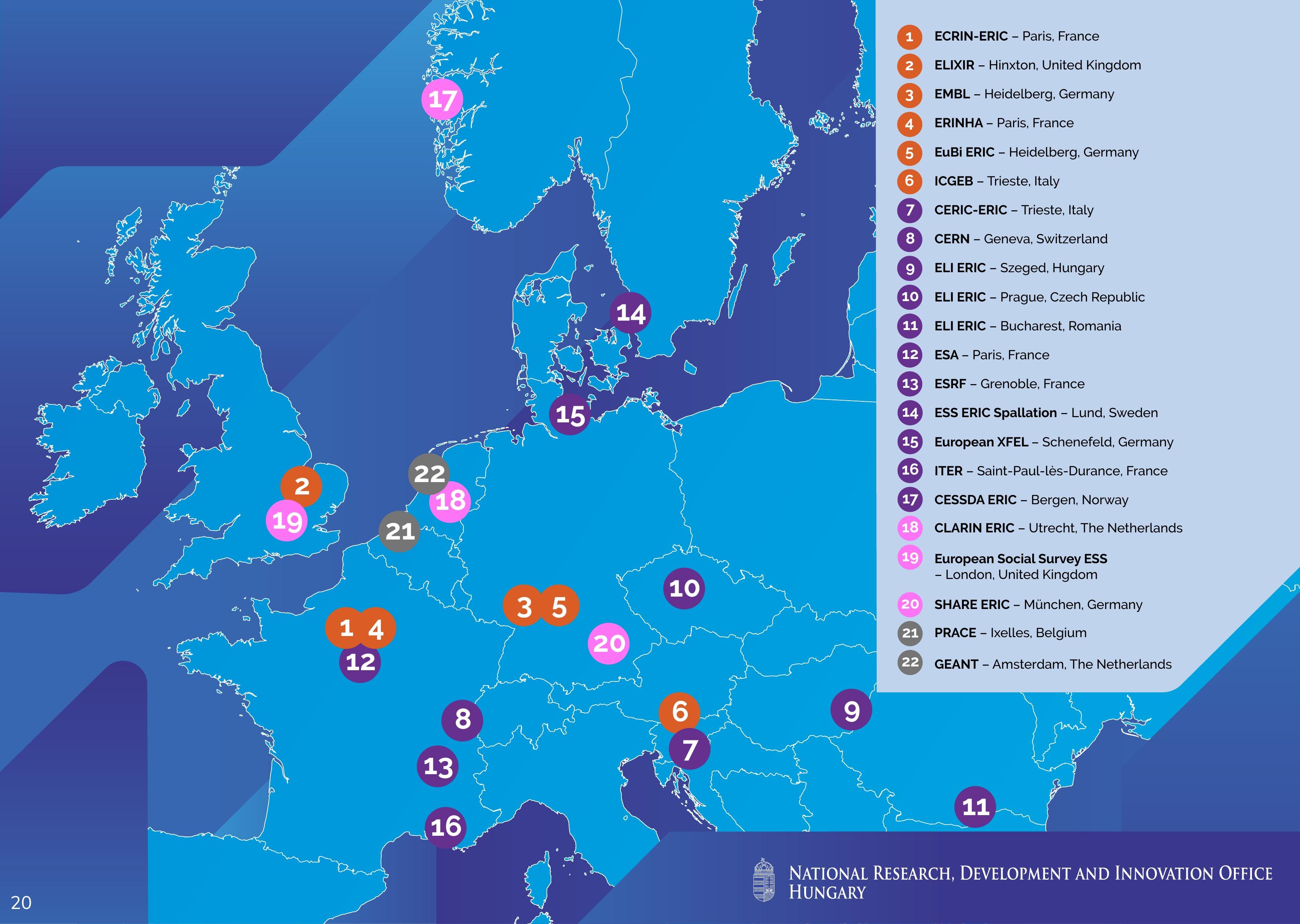





\section{INTRODUCTION TO RESEARCH INFRASTRUCTURES}

One of the key factors in achieving the goals set by a National RDI Strategy is the level of development of the domestic research infrastructures and their embeddedness in the international RI landscape. Therefore investing in RIs is a cornerstone of our national research policy.

RIs have to be viewed as an integral part of a broader ecosystem contributing to the longerterm development of research and innovation and enablers to reduce the "excellence gap". The bridging role of research infrastructures in RDI collaborations and economic development is enhanced by the synergic planning and implementation of different funding sources. The development and networking of research infrastructures in Hungary has been supported by a number of schemes in the past. These have made it possible to expand and update our existing R capacities and to improve their services for research and innovation.

The services provided by research infrastructures to enterprises, SMEs and other actors of the industry can contribute to the development of new technologies, products and services that can have a positive impact on the economy. Unique and cutting-edge scientific facilities can also enhance the mobility of researchers, they have an impact on education and play an important role in the scientific orientation and training of the next generation of scientists. Besides, research infrastructures can serve as tools for implementing 'open laboratory' initiatives and play an important role in the promotion of 'open innovation' efforts.

Through the implementation of the Smart Specialisation Strategy (S3) the research infrastructures will play a key role in the economic development of the regions and will be important factors of our next programming period as well. Their use can greatly enhance cross-border regional and international RDI cooperation.

In this publication we present our national research infrastructures and laboratories of international significance to the broad international research community, which are of key importance in a particular solving strategically important problems, carry out significant research at international level and are actively involved in initiatives and collaborations at European level. 


\section{ENERGY}

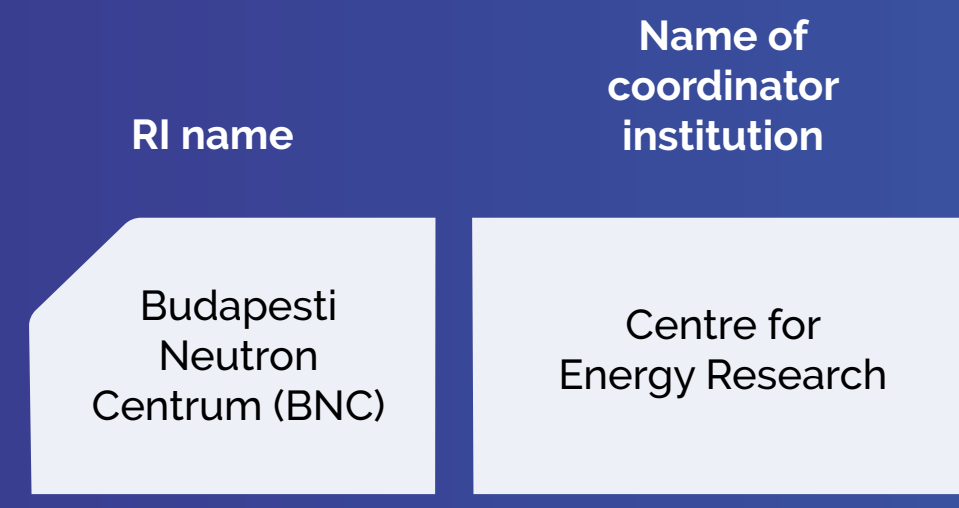

FIEK MVM

Smart Power

Laboratory

\section{Budapest University of Technology and Economics (BME), Center for University-Industry Cooperation (FIEK)}

Modular Hybrid Drive System Laboratory

\section{Budapest University} of Technology and Economics (BME), Center for University-Industry Cooperation (FIEK)

CERIC-ERIC, ESS-ERIC, ILL, Joint Institute for Nuclear Research (JINR)

\section{Budapest}

Budapest

Budapest
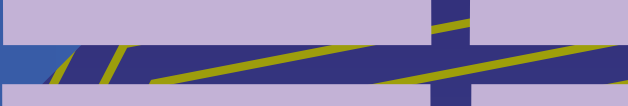

Budapest

\section{International RI connection}

Budapest
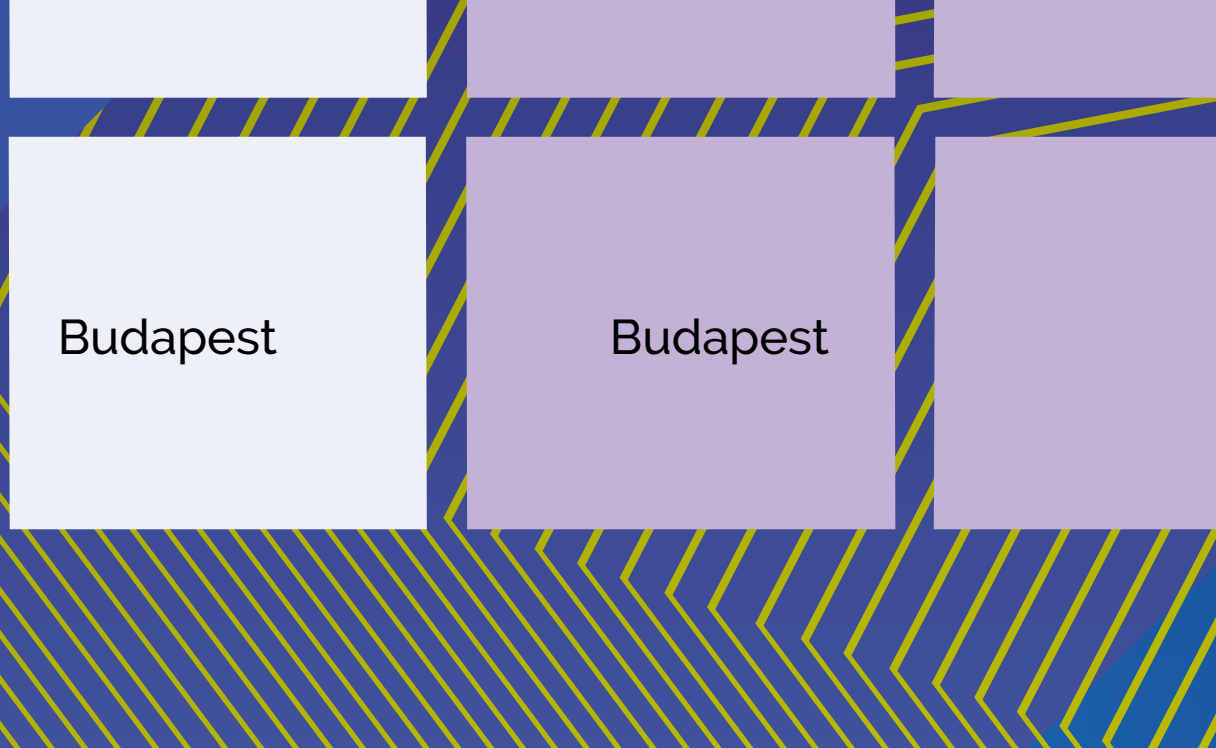

.

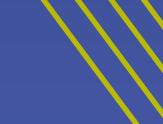



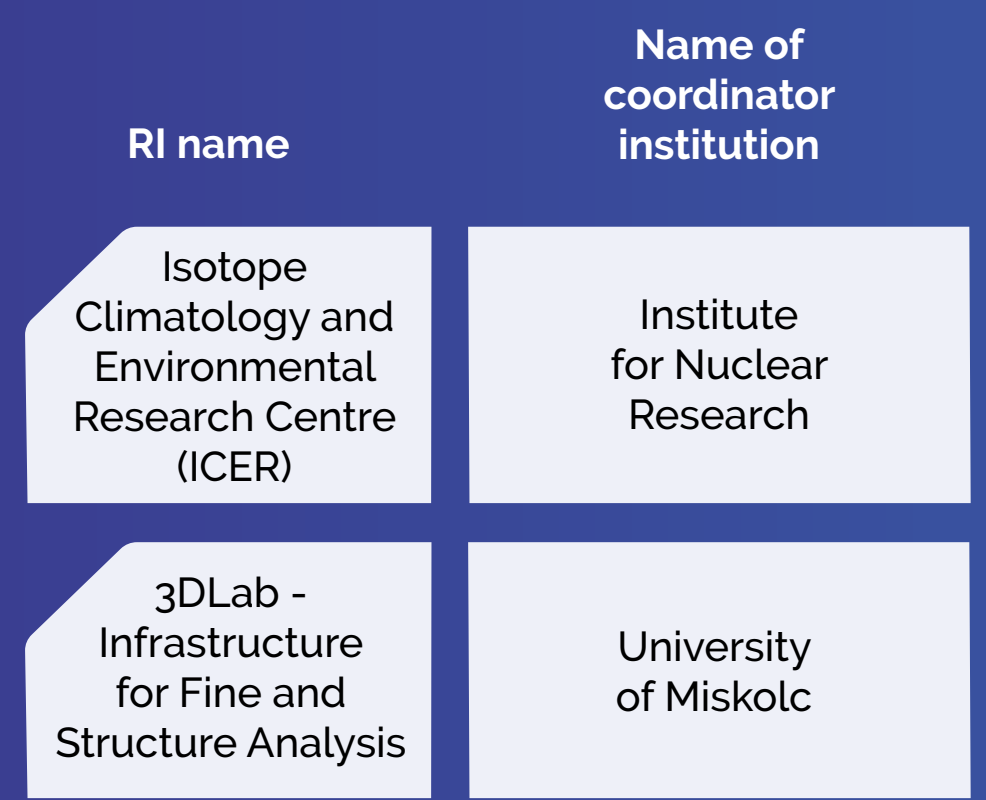

RI site

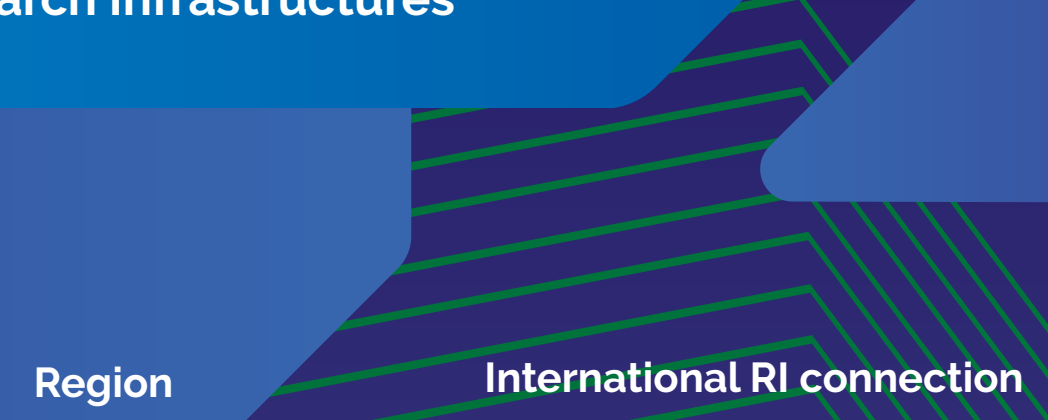

3DLab Infrastructure for Fine and Structure Analysis of Miskolc

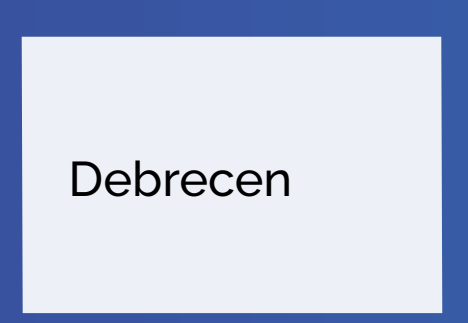

Region

International RI connection
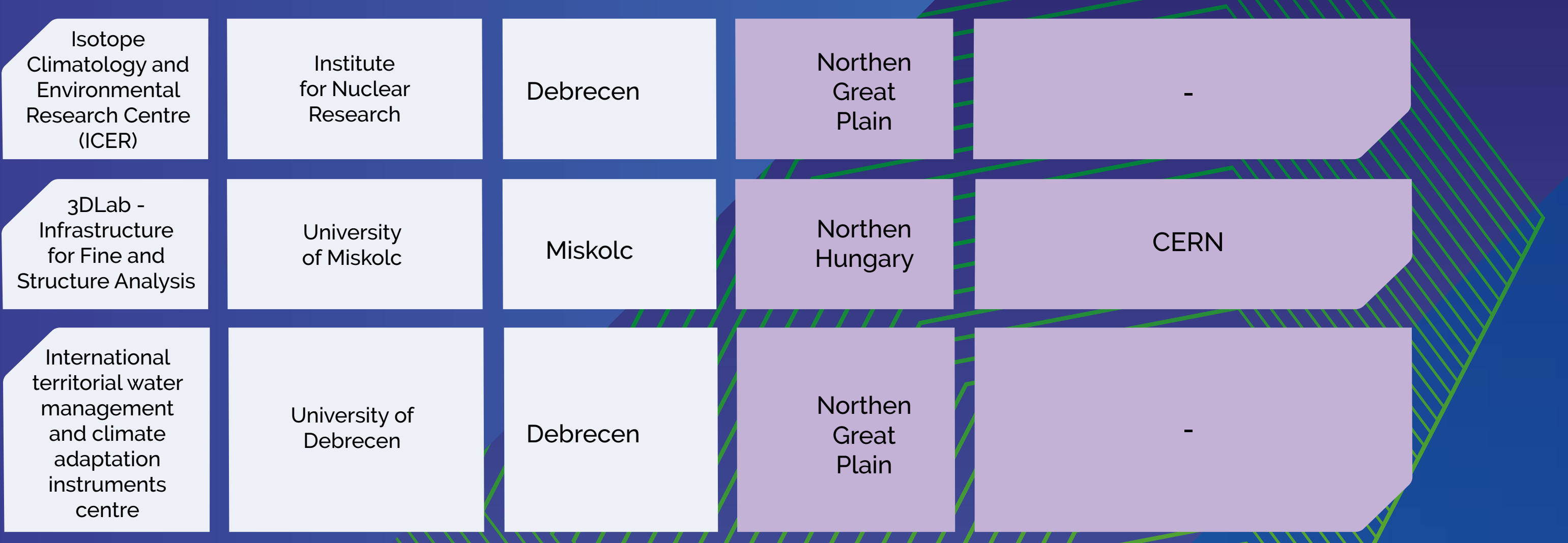


\section{of HEALTH \& FOOD}

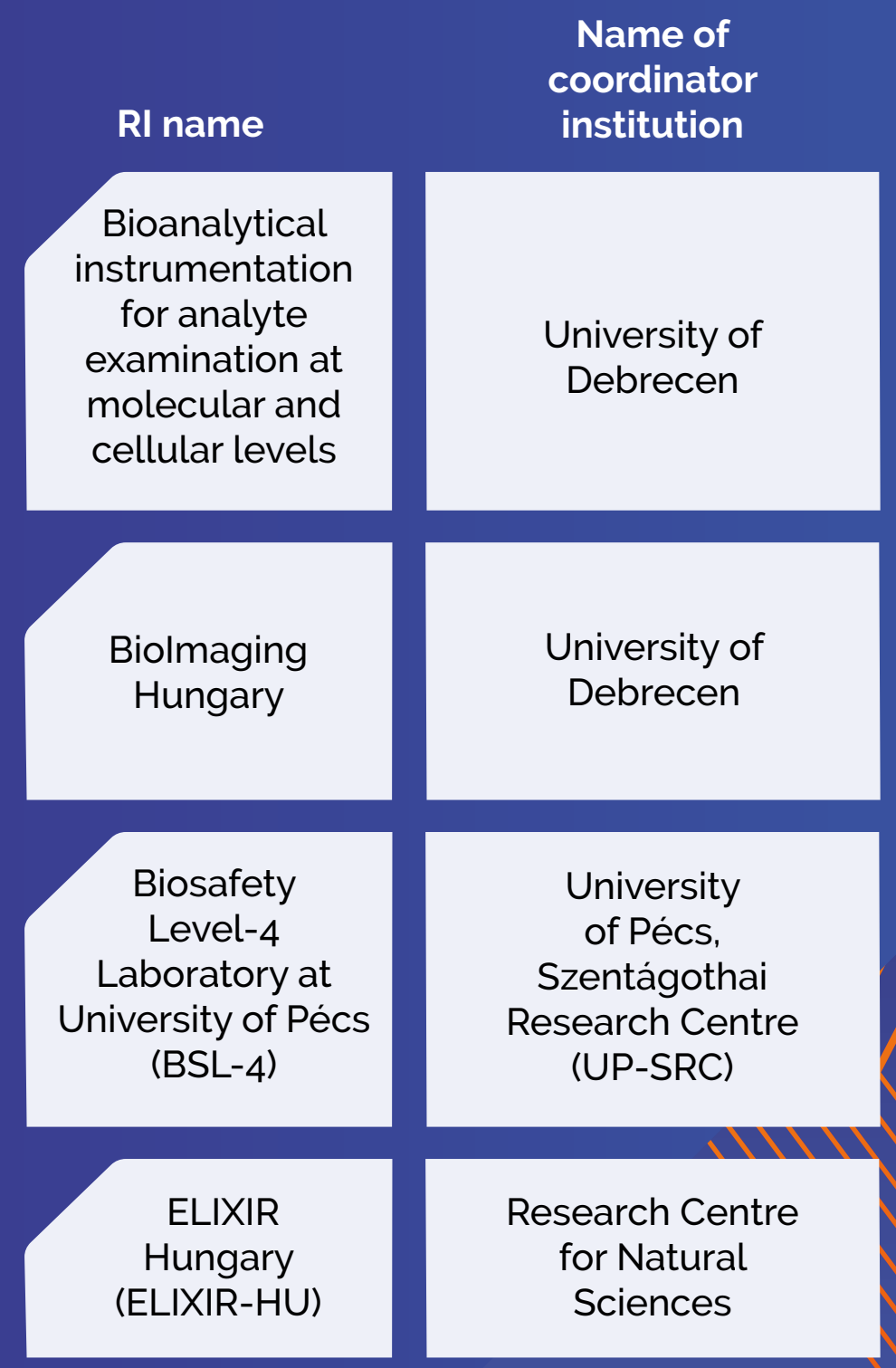

\section{Research Infrastructures}

RI site
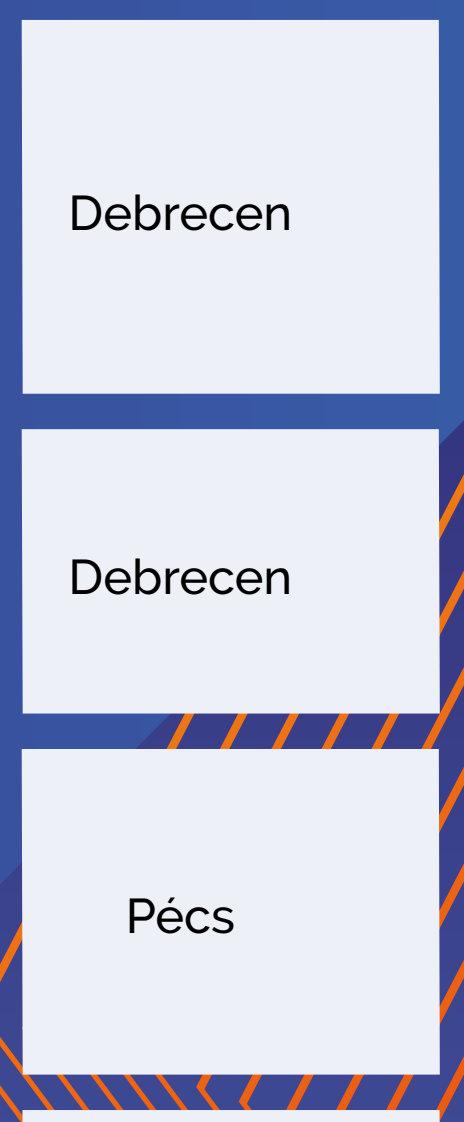

Budapest
NATIONAL RESEARCH, DEVELOPMENT AND INNOVATION OFFICE HUNGARY 


\section{of HEALTH \& FOOD}

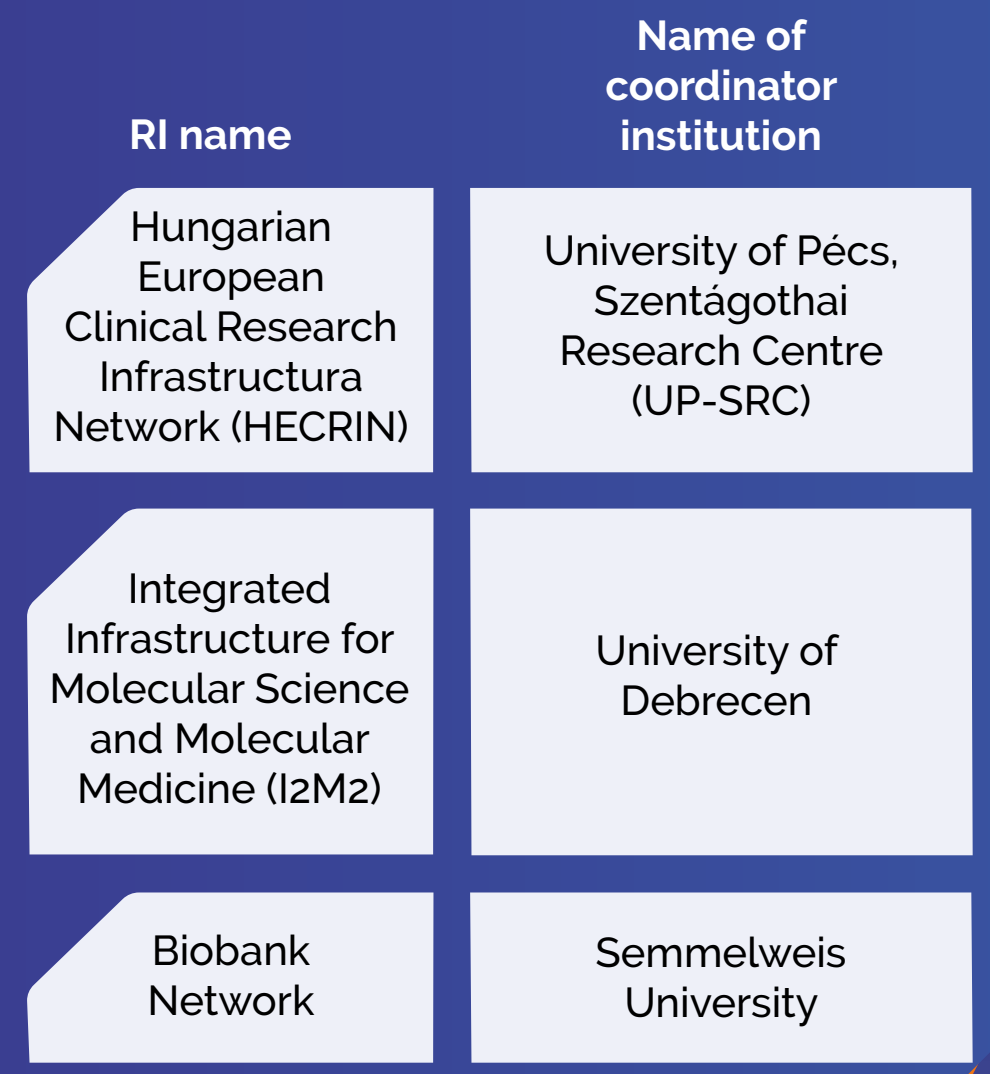

\section{Research Infrastructures}

RI site
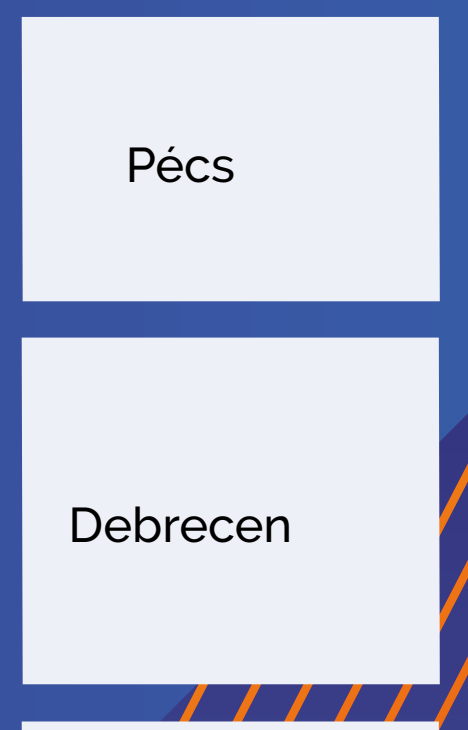

Budapest
International RI connection

Region

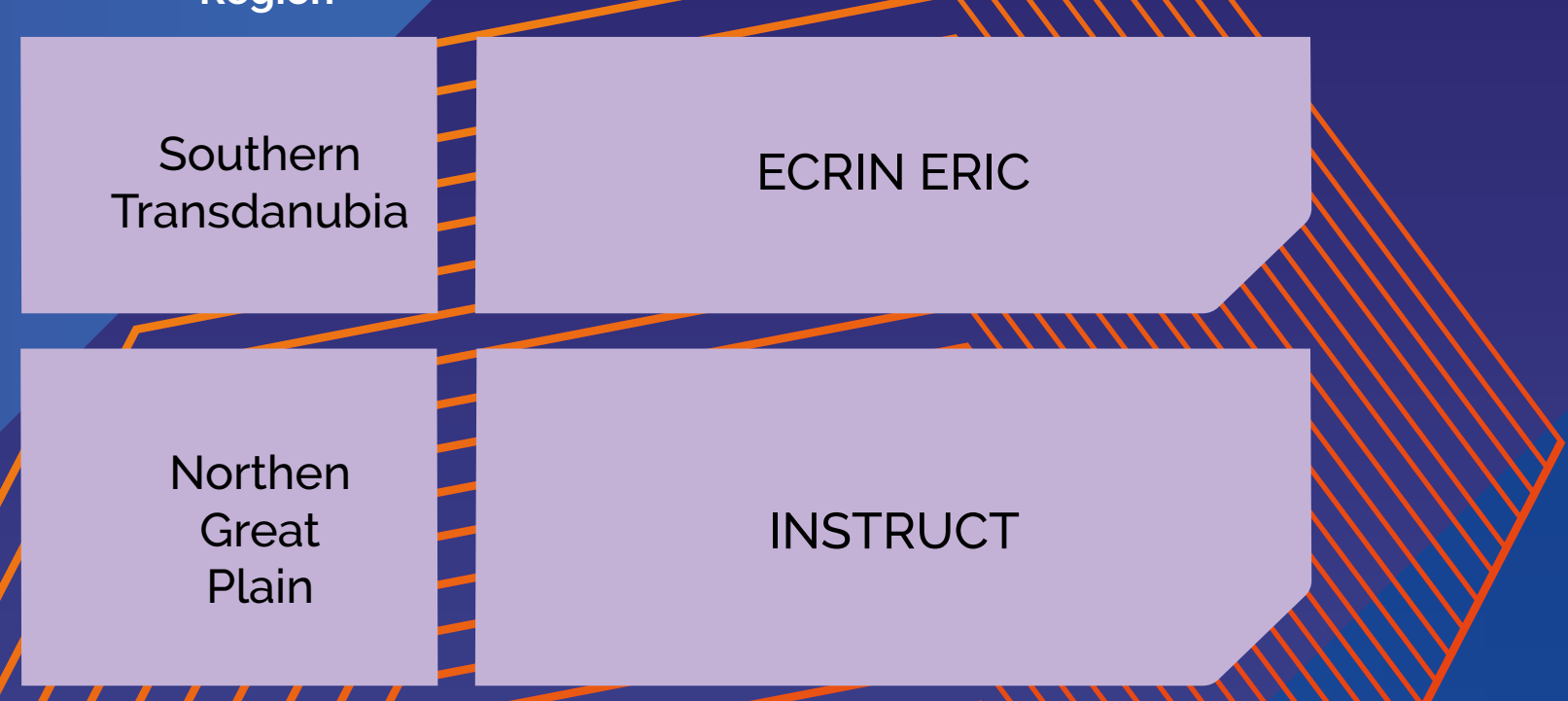

Budapest

BBMRI 


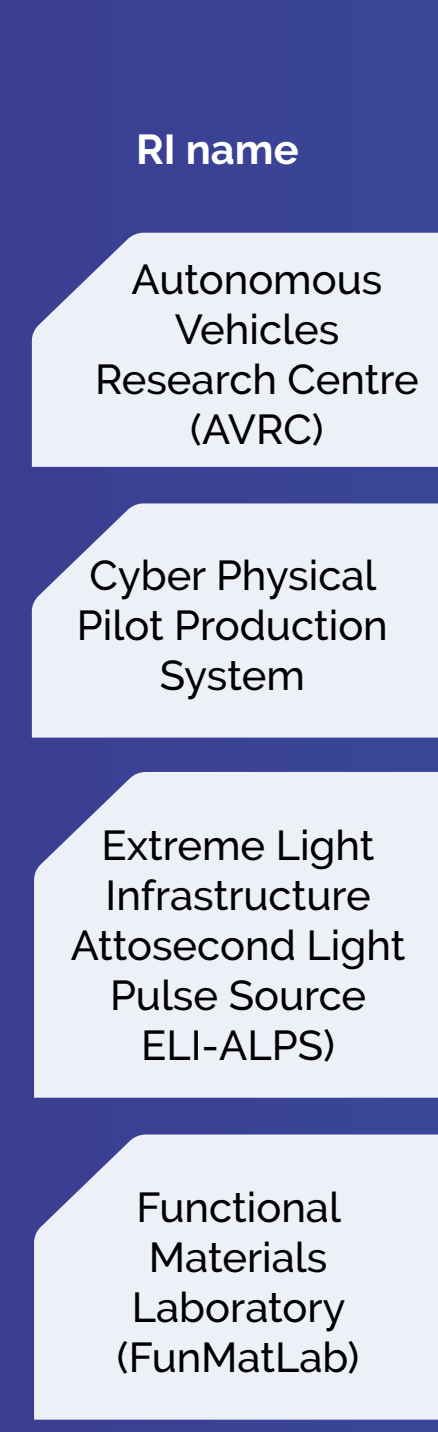

Micro- and Nanotechnology Research Laboratory

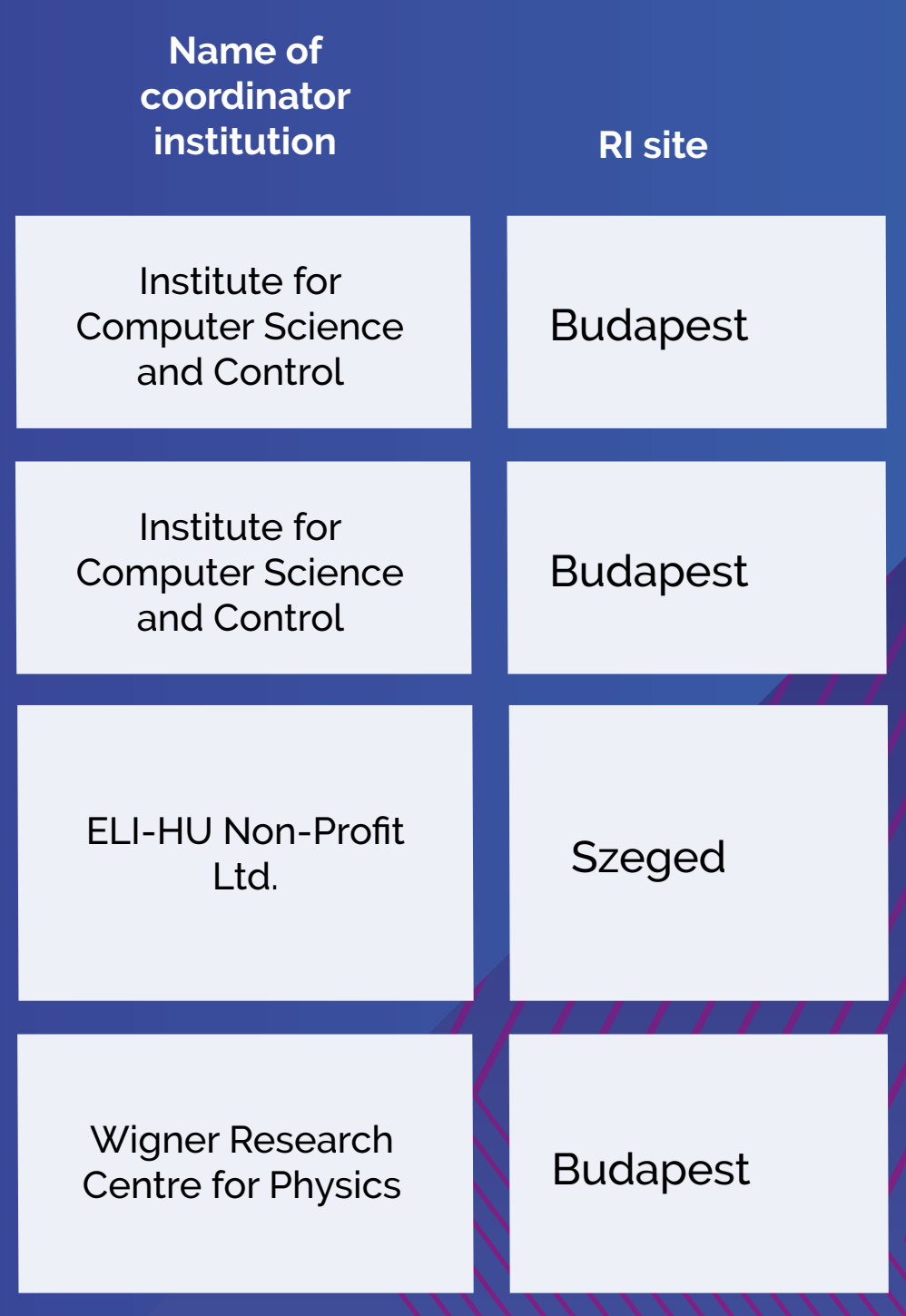

\section{Centre for Energy Research}

\section{Research Infrastructures}

International RI connection
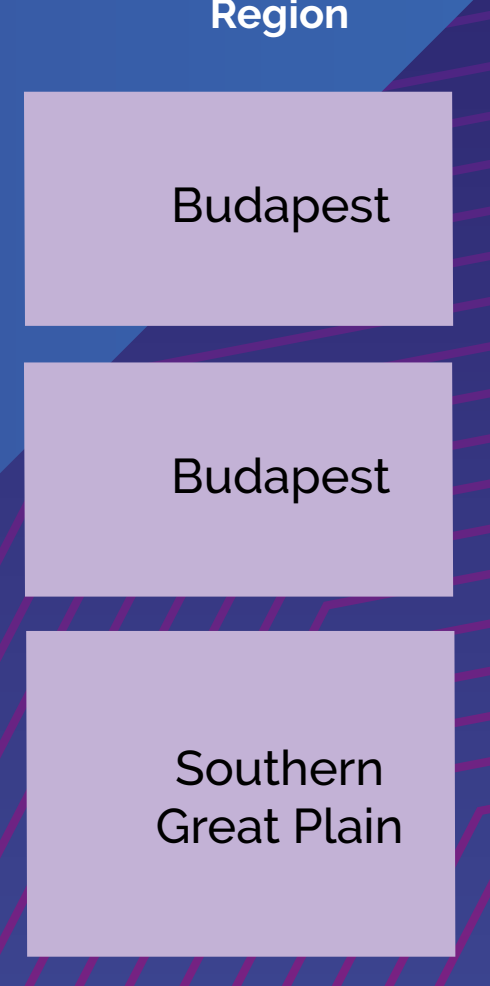

Budapest

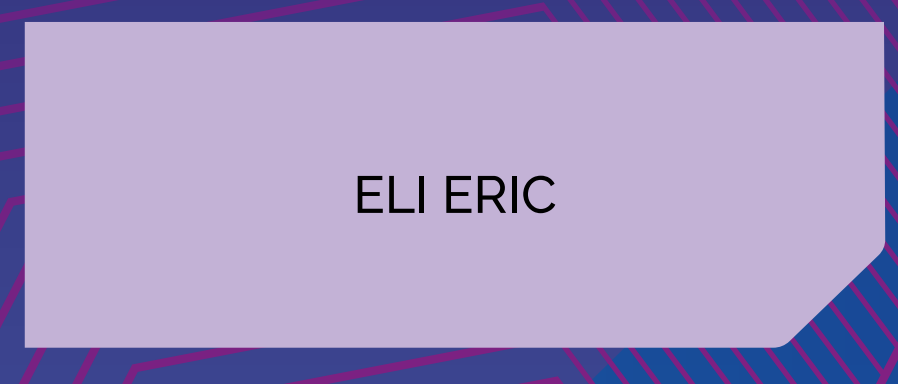

ESRF, EU-XFEL, SwissFEL, ELI-Beamlines

Budapest NATIONAL RESEARCH, DEVELOPMENT AND INNOVATION OFFICE HUNGARY 

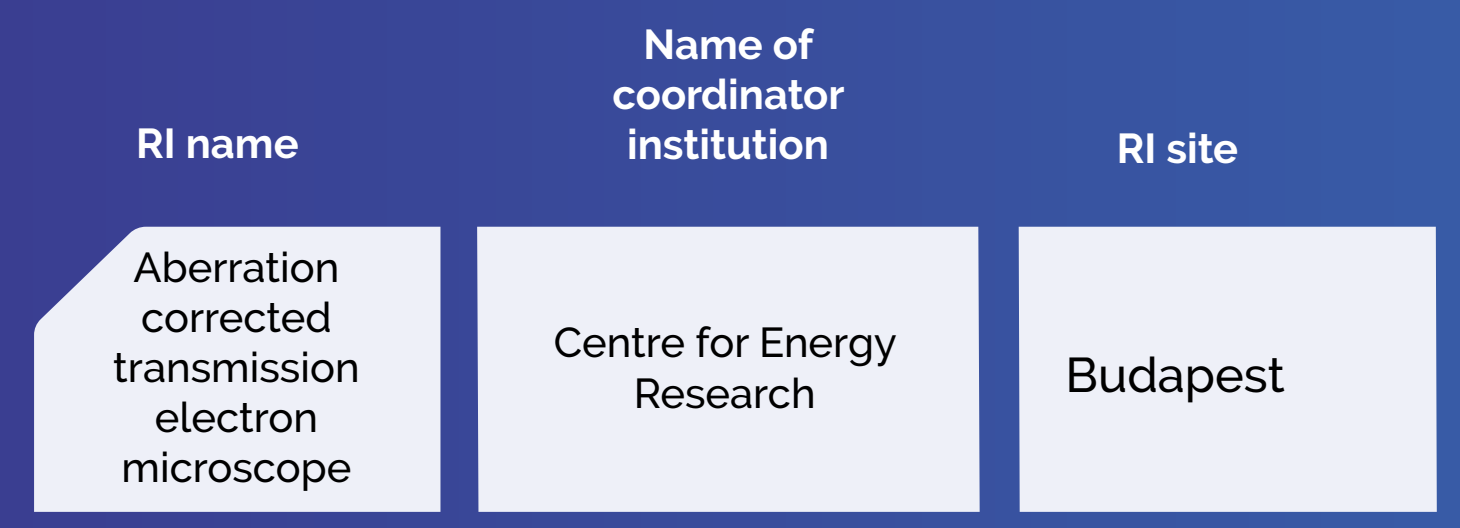

\section{Research Infrastructures}

Machine

Vision and Optical

Perception

Laboratory
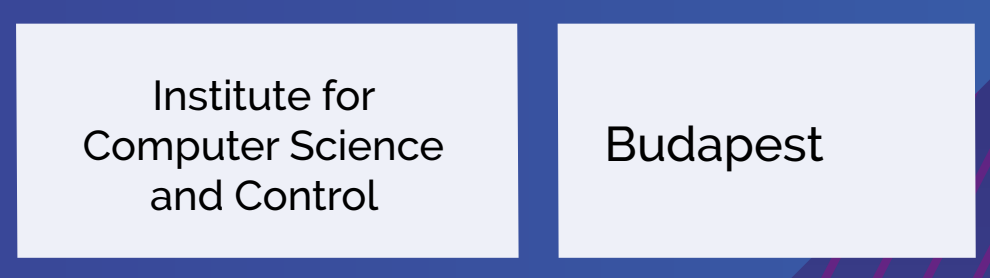

Nanolab

(Electron

Microscopy) at

the University of

Pannonia
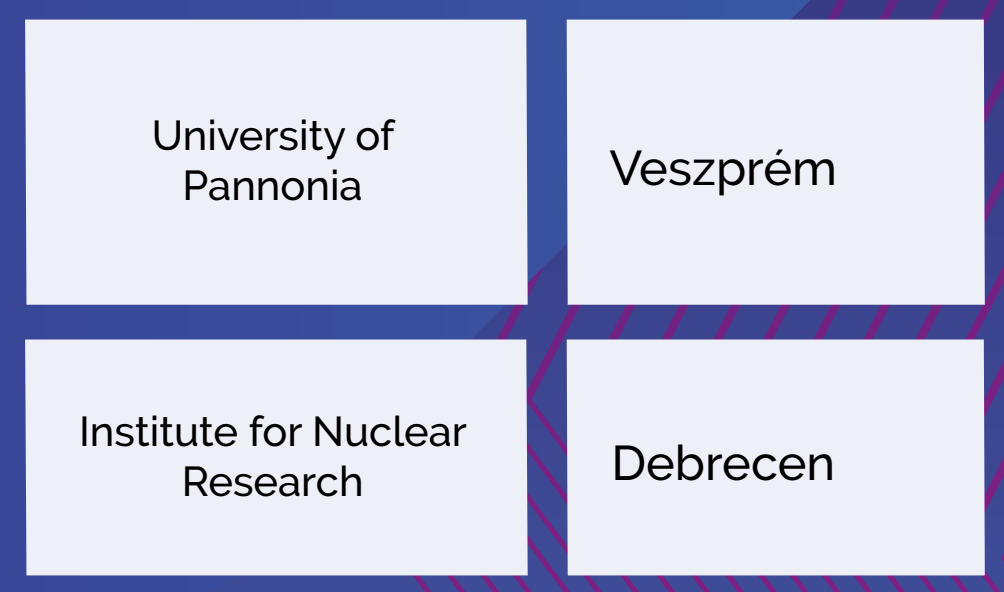

ZalaZONE

Automotive

Proving Ground

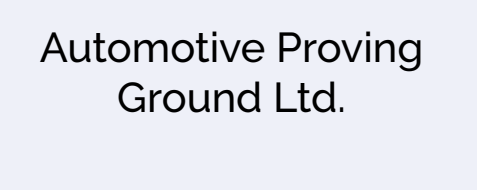

Zala-

egerszeg

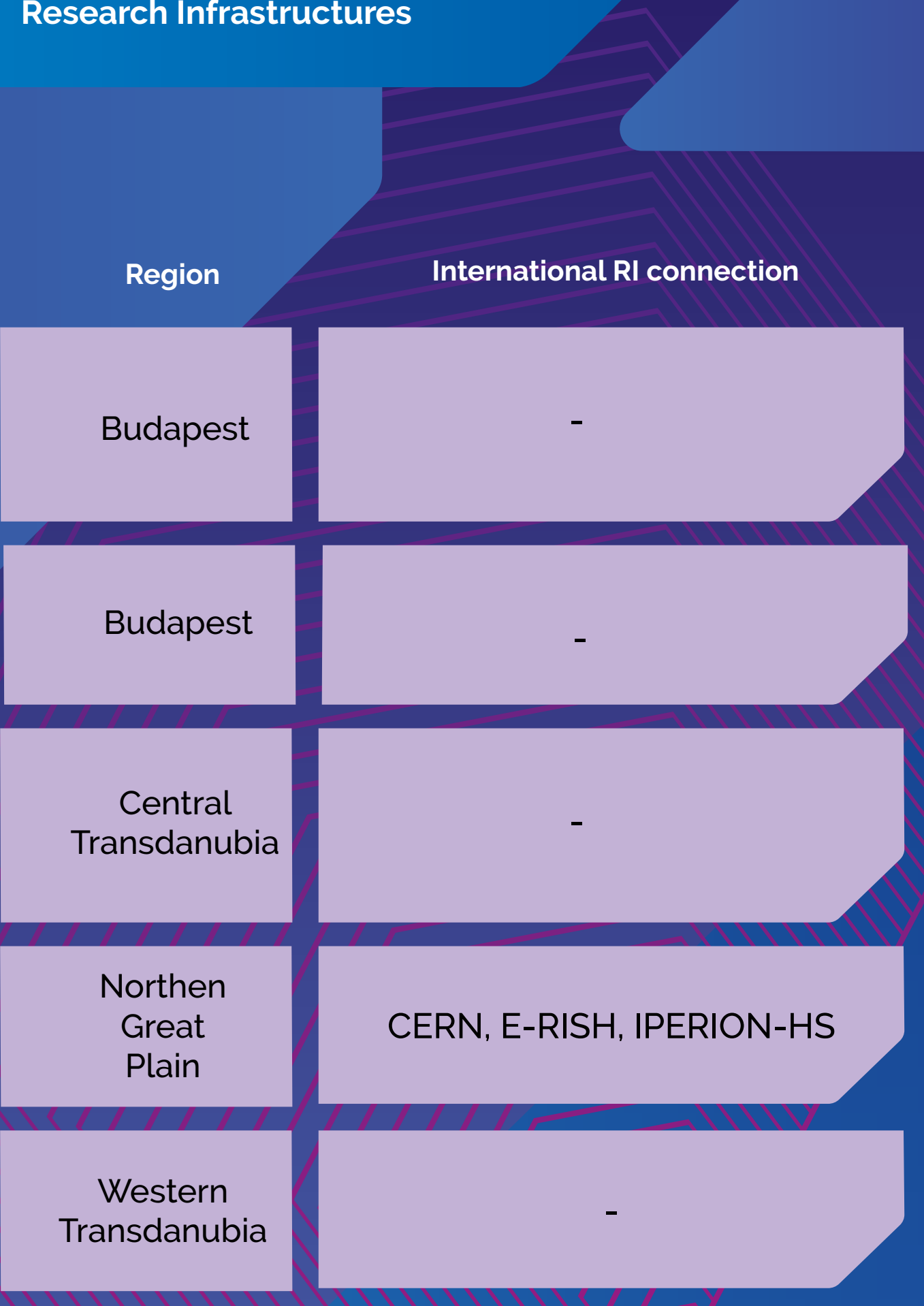




\section{go SOCIAL \& CULTURAL INNOVATION}

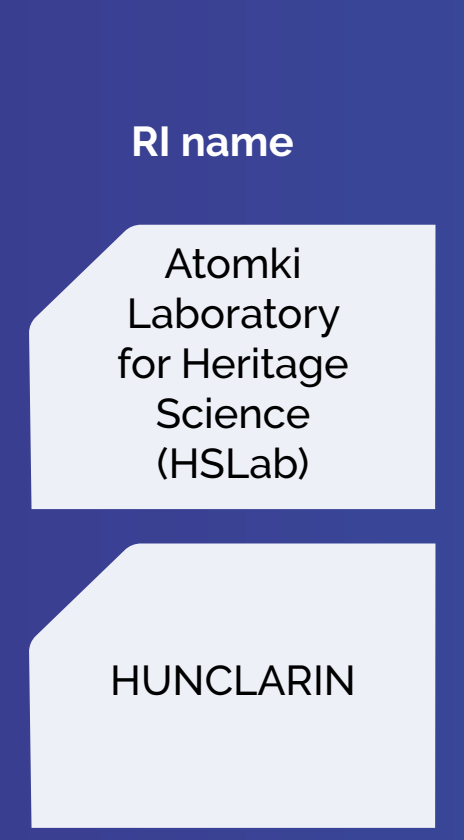

Name of coordinator institution

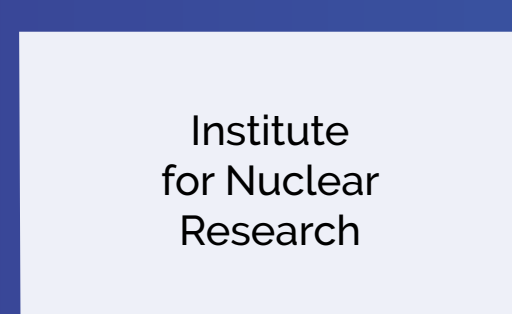

Research Institute for Linguistics
RI site

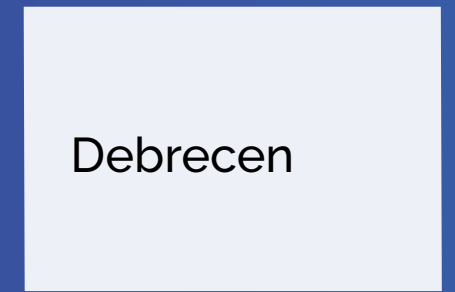

\section{Research Infrastructures}

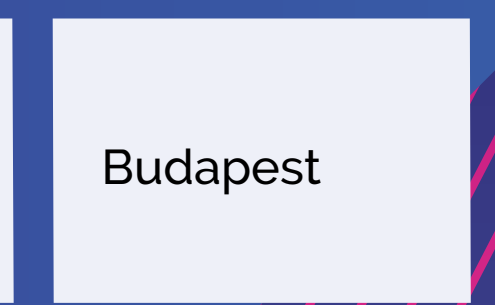

International RI connection
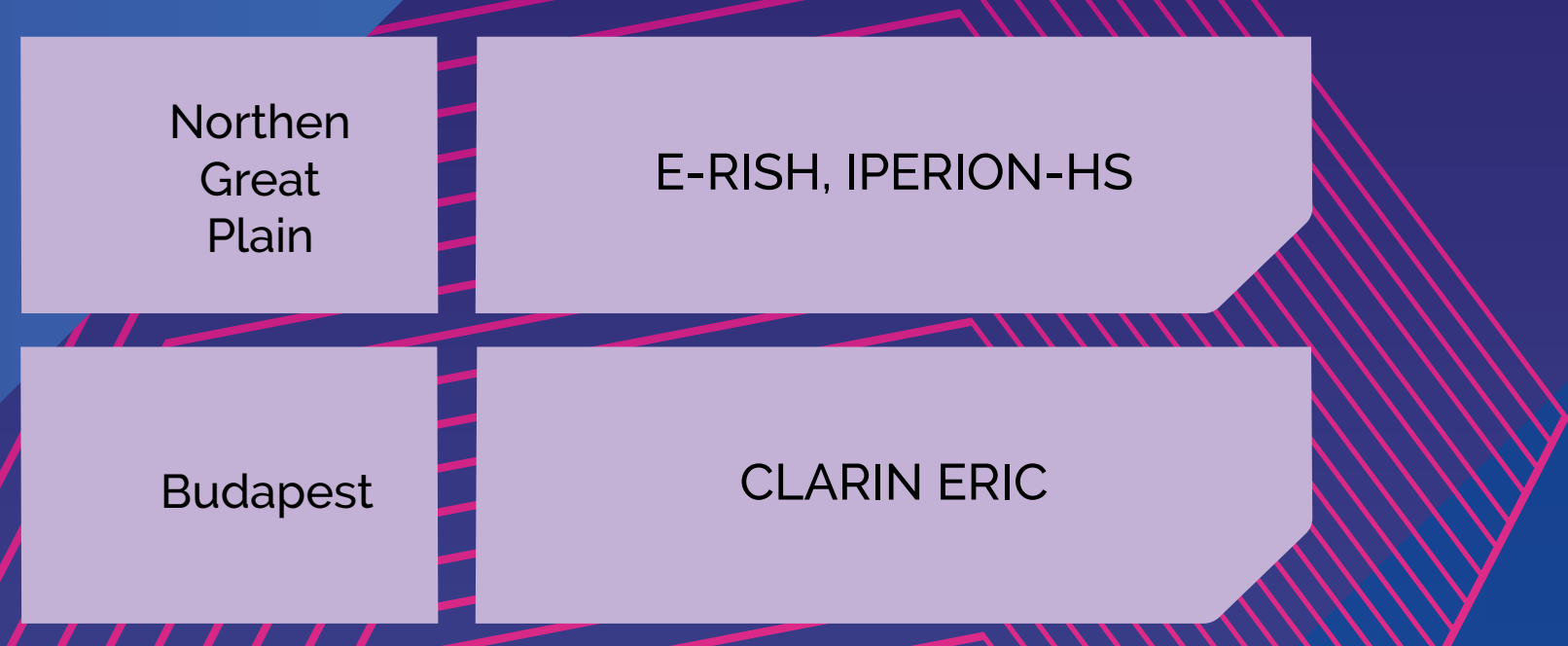


\section{\# DATA, COMPUTING AND Digital RIs}
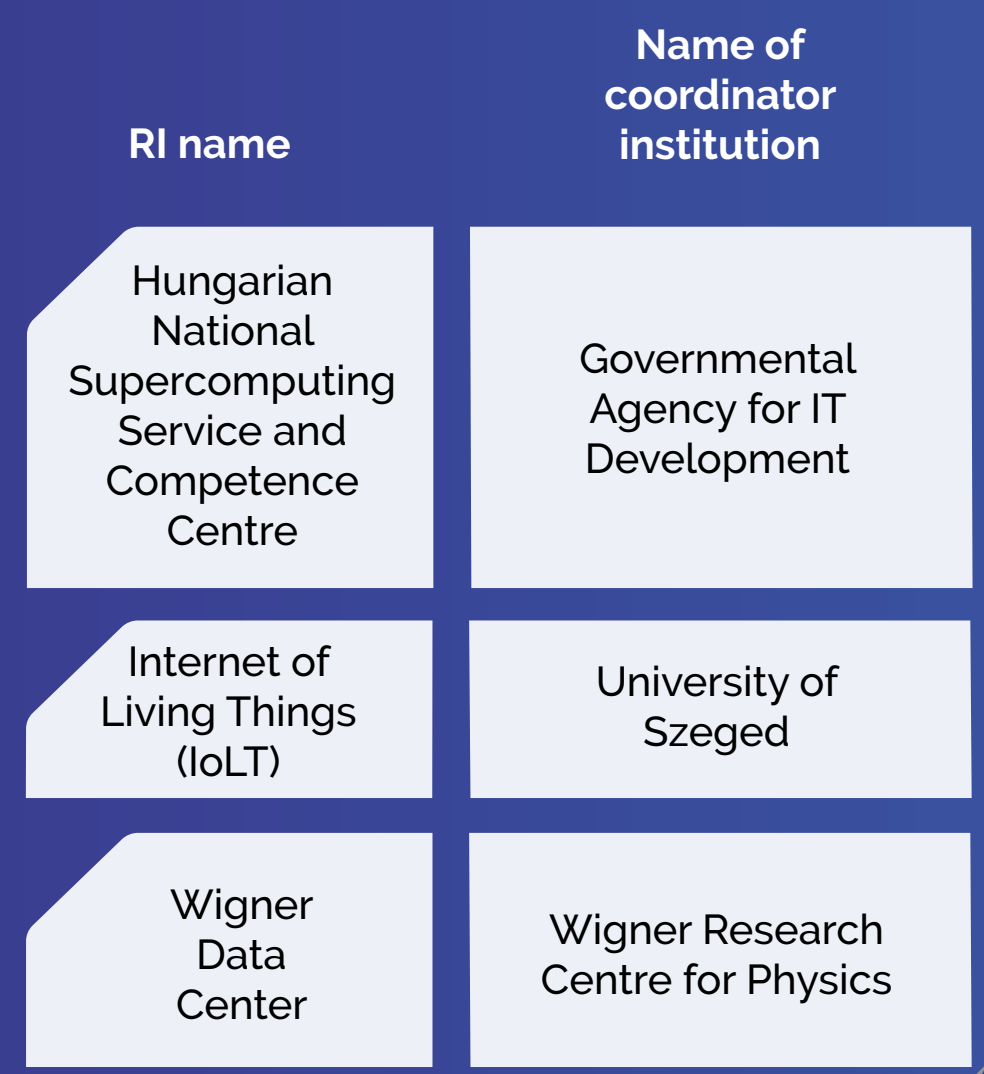

RI site

Research Infrastructures

Governmental

Agency for IT

Development

Debrecen,

Miskolc,

Szeged,

Budapest

GEANT, PRACE, EOSC

$$
\text { Budapest }
$$
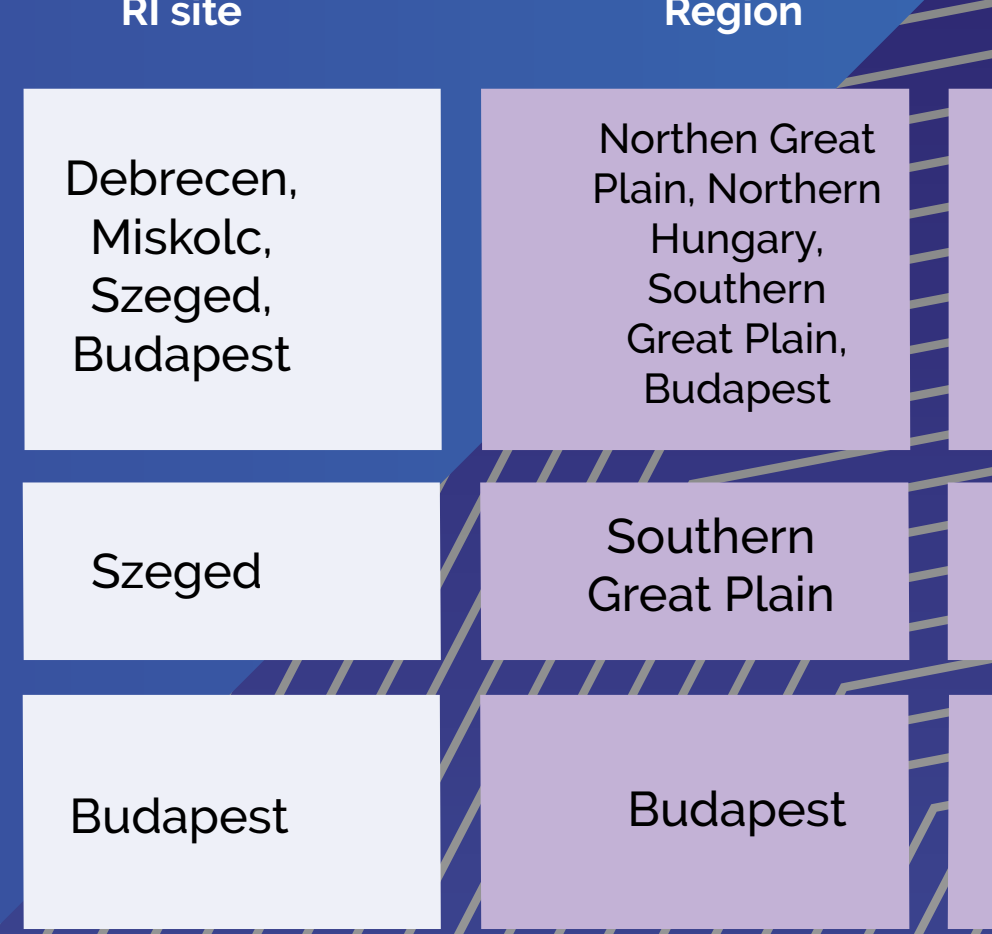

International RI connection

Budapest

\section{Great Plain}

ELI ALPS

Budapest

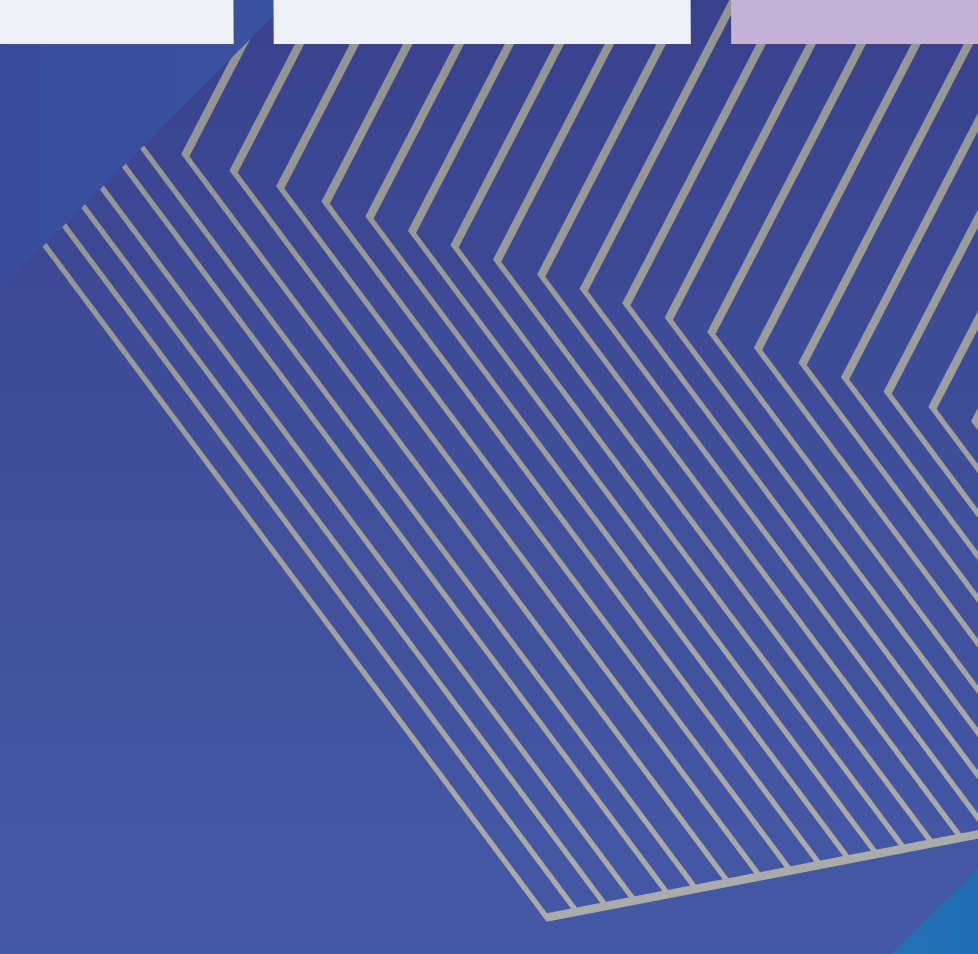

NATIONAL RESEARCH, DEVELOPMENT AND INNOVATION OFFICE 
1 Budapesti Neutron Centrum (BNC) Budapest

(2) FIEK MVM Smart Power Laboratory Budapest

(3) Modular Hybrid Drive System Laboratory Budapest

4 Isotope Climatology and Environmental Research Centre (ICER) Debrecen

5 3DLab- Infrastructure for Fine and Structure Analysis Miskolc

6 International territorial water management and climate adaptation instruments centre Debrecen

(7) Biosafety Level-4 Laboratory at University of Pécs (BSL-4) Pécs

8 Biobank Network Budapest

9 Bioanalytical instrumentation for analyte examination at molecular and cellular levels Debrecen

10 Integrated Infrastructure for Molecular Science and Molecular Medicine (I2M2) Debrecen

11. ELIXIR Hungary (ELIXIR-HU) Budapest

12 Hungarian European Clinical Research Infrastructura Network (HECRIN) Pécs

13 Biolmaging Hungary Debrecen

14 Extreme Light Infrastructure Attosecond Light Pulse Source (ELI-ALPS) Szeged

15 ZalaZONE Automotive Proving Ground Zalaegerszeg

16 Atomki Tandetron Laboratory (ATL) Debrecen

17 Functional Materials Laboratory (FunMatLab) Budapest

18 Nanolab (Electron Microscopy) at the University of Pannonia Veszprém

19 Aberration corrected transmission electron microscope Budapest

20 Micro- and Nanotechnology Research Laboratory Budapest

21 Cyber Physical Pilot Production System Budapest

22 Autonomous Vehicles Research Centre (AVRC) Budapest

23 Machine Vision and Optical Perception Laboratory Budapest
24 Atomki Laboratory for Heritage Science (HSLab) Debrecen

25 HUNCLARIN Budapest

26 Internet of Living Things (IoLT) Szeged

27 Hungarian National Supercomputing Service and

Competence Centre Debrecen, Miskolc Szeged, Budapest

28 Wigner Data Center Budapest 


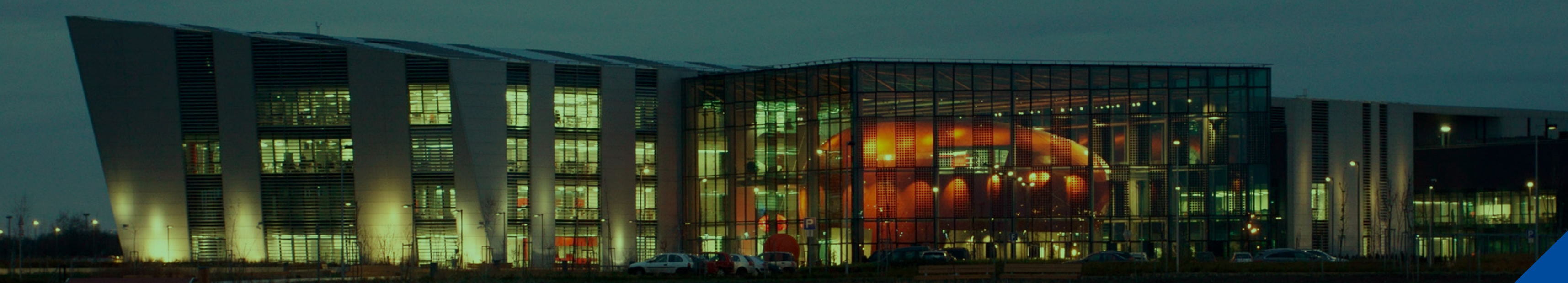

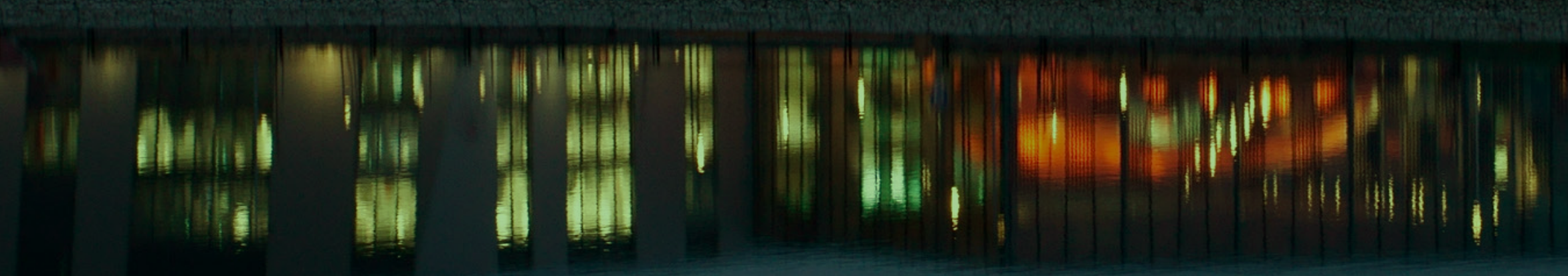

\section{RESEARCH \\ INFRASTRUCTURES IN HUNGARY}




\section{Budapest Neutron Centre}

\section{BNC}

Host institution:

Centre for Energy Research (EK), Eötvös Loránd Research Network

\section{RI location:}

Budapest, KFKI campus

Status:

Fully operational, 1993-

\section{Partners:}

Wigner Research Centre for Physics

International connections: JINR, 'Kurchatov Institute' RIs: CERIC-ERIC, ESS-ERIC, ILL,
Research organizations:

ENSA, ERF-AISBL, LENS; Partners in Cremlin+, IPERION-HS, E-RIHS, TOURR)

\section{Available services:}

17 neutron instruments at the Budapest Research Reactor; related expertise, sample preparation labs \& on-site complementary techniques (X-ray and optical spectroscopy, electron microscopy, etc.)

\section{Website:}

https://www.bnc.hu/

\section{Person in charge:}

Ákos Horváth, Director General of EK horvath.akos@energia.mta.hu

Contact:

Tamás Belgya, Director of BNC belgya.tamas@energia.mta.hu EU projects (H2O2O currently: ARIEL,

\section{Activities and services}

The Executive Board of BNC coordinates the research activities and assists the EK management in strategy-building, promotion, industrial outreach, with regvular support from the International Scientific Advisory Council (ISAC), an independent body consisting of renowned European scientists. An international User Selection Panel (USP) assesses the scientific excellence of experimental proposals submitted twice a year to the RI. The User Office administers the proposals, evaluations, research reports, publications, technically manages user visits and occasional events. The vinstrument scientists perform the user experiments, carry out own research projects, develop and promote their instrument.

Neutron scattering, spectroscopy, activation and imaging methods can reveal the nano/ micro/macro-structure or the composition of materials. BNC offers excellence-based open access to 17 experimental stations within the international user programme, applicable to basic and applied research in physics, materials science, chemistry, health and biology, radiation protection, engineering, and cultural heritage. The RI provides internationally competitive research opportunities for about 200 domestic and over 500 neutron-users in Central-Europe. The results get published in peer-reviewed articles, M.Sc. or Ph.D. theses, grant-related research reports, popular science notes, and in the social media. The RI's methodical and instrumental developments are regularly transferred to SMEs to generate revenue. BNC has been a particularly successful participant of EU research infrastructure programmes, as it was beneficiary of over $20 \mathrm{EU}$ framework projects since $\mathrm{FP}_{5}$ (NMI3 CHARISMA, BrightnESS, etc.) and numerous national and international bilateral projects.

The Executive Board of BNC coordinates the research activities and assists the EK management in strategy-building, promotion, industrial outreach, with regvular support from the International Scientific Advisory Council (ISAC), an independent body consisting of renowned European scientists. An international User Selection Panel (USP) assesses the scientific excellence of experimental proposals submitted twice a year to the RI. The User Office administers the proposals, evaluations, research reports, publications, technically manages user visits and occasional events. The instrument scientists perform the user experiments, carry out own research projects, develop and promote their instrument.

Neutron scattering, spectroscopy, activation and imaging methods can reveal the nano/ micro/macro-structure or the composition of materials. BNC offers excellence-based open access to 17 experimental stations within the international user programme, applicable to basic and applied research in physics, materials science, chemistry, health and biology, radiation protection, engineering, and cultural heritage. The RI provides internationally competitive research opportunities for about 200 domestic and over 500 neutron-users in Central-Europe. The results get published in peer-reviewed articles, M.Sc. or Ph.D. theses, grant-related research reports, popular science notes, and in the social media. The RI's methodical and instrumental developments are regularly transferred to SMEs to generate revenue. BNC has been a particularly successful participant of EU research infrastructure programmes, as it was beneficiary of over $20 \mathrm{EU}$ framework projects since FP5 (NMI3, CHARISMA, aa BrightnESS, etc.) and numerous national and international bilateral projects

A recent Government-provided fund enabled purchasing fresh fuel for the continued operation of BRR. A service life extension programme aims at prolonging its operational license until 2033. In parallel, BNC is about to modernize its existing beamline facilities and install some new unique/world-class instruments, within the National Laboratory nitiative of the NRDI Office. 


\section{FIEK MVM Smart Power Laboratory}

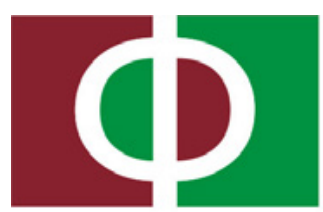

BME FIEK

Host institution:

Budapest University of Technology and Economics (BME), Center for University-Industry Cooperation (FIEK)

\section{RI location:}

Budapest, BME campus Bldg V1

Status:

Fully operational, 2018

\section{Partners:}

MVM Group, MVM Hungarian Electricity Private Limited Company (MVM Zrt.)

International connections: RIs: RWTH Aachen University, Institute for Automation of Complex Power Systems
Available services:

PHIL testing, HIL testing, rapid prototyping of controllers, relays in multidomain real time simulation environment. Hybrid simulation of microgrid in island and grid parallel mode. Testing grid support: virtual inertia, island detection and resynchronization. Analyzing PV and storage in voltage control and power sharing, consumers with variable demand, variable power factors, harmonic distortion, asymmetry. Energy management in $A C$ and DC microgrid.

Website:

https://www.fiek.bme.hu/

\section{Person in charge:}

László Lengyel, Director of BME FIEK lengyel@aut.bme.hu

Contact:

Dr. Dávid Raisz, PhD, Head of Smart Power Laboratory. raisz.david@vet.bme.hu

\section{Description of the research infrastructure}

During the FIEK project (April 2017 - March 2021). MVM and BME established a unique and specialized laboratory which provides ideal conditions for Power-Hardware-in-the-Loop testing of smart power solutions, up to $400 \mathrm{VAC}$ and $750 \mathrm{~V}$ DC in $30 \mathrm{kVA}$ power range. It consists of a Real-time power system simulator, a four-quadrant linear amplifier, several controllable converters, a grid emulator, electronic load, battery emulator, and several measurement and control units.

\section{Activities and services}

Power Hardware-In-The-Loop testing, microgrid control (PHIL), controller and protection testing. Model-In-The-Loop: Fast simulation of power systems, simulation in Electromagnetic transient (EMT) and phasor modes (RMS). Realization of virtual inertia in a PV system (microgrid) and participation in frequency control. Synchronization and joint island operation of multiple inverters. Voltage control and power sharing between PV and storage subsystems, effects of solar or storage inverters on system dynamics. Fail-safe design of communication-based control systems

Core equipment are:

- OP5700 real-time computer with 8 physical CPU cores, Virtex 7 FPGA board 64 digital inputs, 64 digital outputs, 32 analog inputs and 32 analog outputs. IEC61850,

IEC60870-5-104, Modbus RTU. OP8710 High Voltage Solid State Relay box. SW: EMEGASIM, ePHASORSIM, eFPGASIM.

$$
\mathrm{P}+4 \mathrm{Q} \text { Three phase power amplifier with 7kVA per phase, } \mathrm{DC}-25 \mathrm{kHz} \text {. }
$$

Regenerative type controllable inverters with variable filter structure and converter topology, generic inverters for testing new control algorithms:

$\mathrm{NI}$-Triphase: AC Active Front-end, bidirectional, 3x $24 \mathrm{~A}$.

Imperix BoomBox, 8x PowerTrench PEB8032 power modules (800V), HIL

Simulator interface for Opal-RT, automated code generation toolbox for Matlab Simulink. - Cinergia grid emulator, battery emulator, electronic load in 20-30 kVA range.

- Danfoss FC302 automation drive inverters + dSpace sw tools. OMICRON CMS356 linear amplifier.

Measurement and data logging:

- LabView National Instruments Crio,

- DEWE2-PA7 network analyzer.

LECROY - WAVESURFER 104MXS

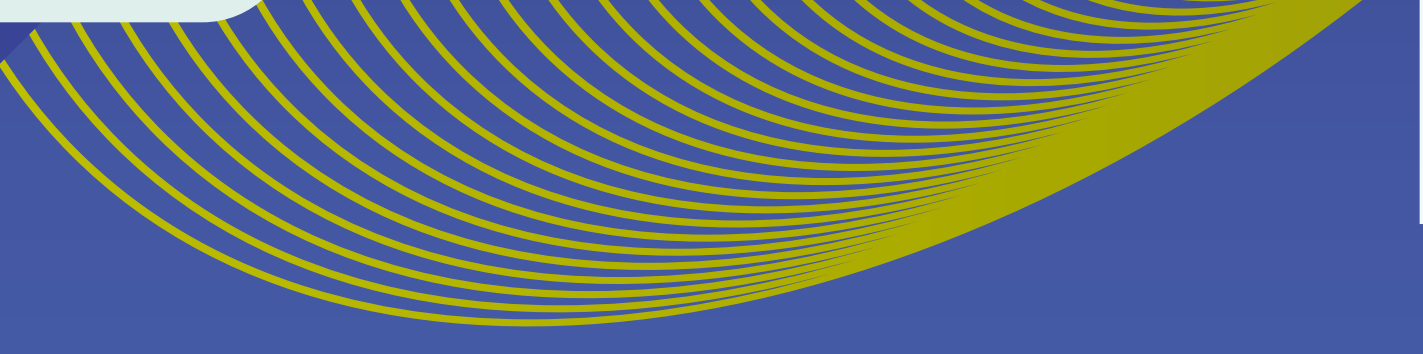




\section{Modular Hybrid Drive System Laboratory}

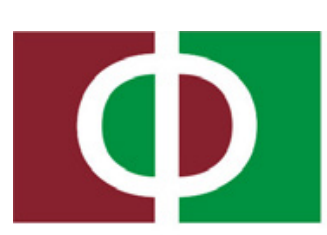

BME FIEK

\section{Host institution:}

Budapest University of Technology and Economics (BME), Center for University-Industry Cooperation (FIEK)

\section{RI location:}

Budapest, BME campus

Status:

Fully operational, 2020-

\section{Partners:}

Siemens Zrt,
Rolls-Royce Hungary Kft.
Available services:

E-vehicle system and component testing; related expertise, Power Hardware in the Loop equipment \&

\section{Website:}

https://fiek.bme.hu/english

\section{Person in charge:}

László Lengyel, Director of BME FIEK lengyel@aut.bme.hu

\section{Contact:}

fiek@mail.bme.hu on-site complementary techniques

\section{Description of the research infrastructure}

Nowadays the wide spreading of electric vehicles generated the need for special power electronics equipment for testing electric vehicles' powertrain. Our mission is to follow the demands of the industry and fulfil the requirements with the highest quality. Productive research and development of the last few years made possible to build the modular hybrid drive system laboratory at the BME campus. With our special self-developed technology we are able to perform tests on any part of the powertrain in the $300 \mathrm{~kW}, 1200 \mathrm{~V}$ and 15000 RPM range. In the future we are going to extend the functionalities not only for electric vehicles but also for any power electronics devices and continuously install high accuracy voltage, current, power and temperature analysing equipment.

The Modular Hybrid Drive System Laboratory was commissioned in 2020 and it is available for E-vehicle developers for drive system and drive component testing

\section{Activities and services}

Our laboratory focuses on two purposes. For companies we provide extensive testing possibilities for complete powertrain systems and powertrain components like motors, generators, power converters, batteries and inverters among many others. With our special high voltage and high power PHIL (Power Hardware In the Loop) system we are able to emulate rotating machines and various speed sensors with flexible user settable electrical and mechanical parameters. We can provide forced air cooling and liquid cooling solutions which fits most of the existing devices. On-site complementary services and our trained power electronics and power control experts are available for support.

We also provide internationally competitive research opportunities for domestic and for foreign users in Central-Europe. The results can be published in peer-reviewed articles, M.Sc. or Ph.D. theses, grant-related research reports, popular science notes, and in the social media. The possible research area includes multilevel high performance converters power control, PHIL systems, new control strategies and HIL systems. For researchers we have numerous national and international bilateral and industrial projects.

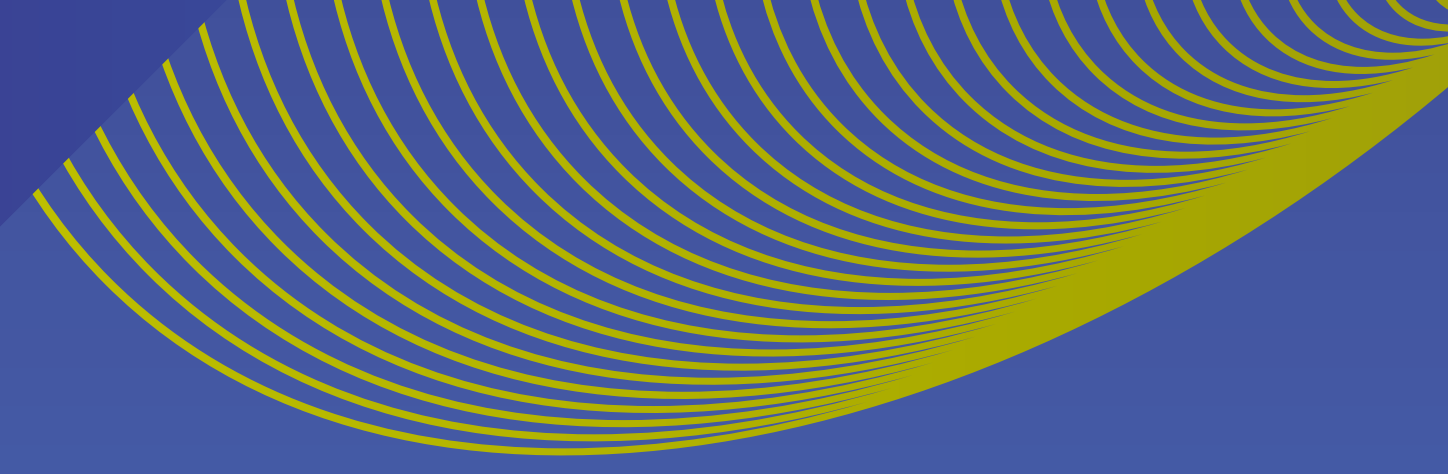

NATIONAL RESEARCH, DEVELOPMENT AND INNOVATION OFFICE HUNGARY 


\section{Isotope Climatology and Environmental Research Centre (ICER)}

Host institution:

(Atomki), Eötvös Loránd Research Network

\section{RI location:}

Debrecen

Status:

International connections:

ETH Zürich, IUP Heidelberg

University of Arizona

\section{Available services:}

isotope analyses of different materials; stable isotope ratio measurements of hydrogen

$(2 \mathrm{H})$, carbon (13C), nitrogen(15N), oxygen(18O), sulphur(34S) by IRMS stable isotope ratio measurements of hydrogen $(2 \mathrm{H})$ and oxygen $(17 \mathrm{O}, 180)$ by cavity enhanced laser spectroscopy; isotope ratio measurements of copper $(65 \mathrm{Cu} / 63 \mathrm{Cu})$, hafnium

$(176 \mathrm{Hf} / 177 \mathrm{Hf})$

neodymium, lead,

Website:

https://iker.atomki.hu/en/

Person in charge:

Zsolt Dombrádi, director director@atomki.hu

Contact:

László Palcsu

head of ICER

palcsu.laszlo@atomki.hu
Institute for Nuclear Research

Fully operational

strontium (87Sr/86Sr) and uranium by MC-ICPMS; tritium by the $3 \mathrm{He}$ ingrowth method; $14 \mathrm{C}$ by AMS; noble gases including $3 \mathrm{H} / 4 \mathrm{He}$ ratio dissolved in water; $3 \mathrm{H} / 3 \mathrm{He}$ age determination: $\mathrm{K} / \mathrm{Ar}$ and $\mathrm{Ar} / \mathrm{Ar}$ dating; 230Th/234U dating; clumped isotope analysis $(\Delta 47)$ of carbonates;

\section{Description of the research infrastructure}

The Isotope Climatology and Environmental Research Centre (ICER) as a project and as a laboratory started in 2016. Since then, new state-of-the-art isotope analytical instruments have been installed and used in environmental and earth sciences, together with existing mass spectrometers. The ICER covers a wide dynamic research field from past climate to recent environmental chemistry. Related topics are organized necessarily around a major group of instruments (mainly mass spectrometers) or a certain method. The research direction of ICER involves those multidisciplinary topics in which physical methods can be applied in other fields (geology, hydrology, meteorology, biology, history and environmental protection) to fulfil the aim of the project.

\section{Activities and services}

The inorganic mass spectrometers in the ICER research infrastructure are used in the field of isotope geochemistry, environmental chemistry and geochronology. Two stable isotope ratio mass spectrometer is responsible for the $\mathrm{H}, \mathrm{C}, \mathrm{N}, \mathrm{O}$ and $\mathrm{S}$ isotope ratio determination (DeltaPLUS XP), as well as clumped isotope $(\triangle 47)$ thermometry of carbonates (MAT253 PLUS). A high resolution MC-ICPM (Neptune PLUS) is used to determine various isotope ratios, such as $65 \mathrm{Cu} / 63 \mathrm{Cu}, 176 \mathrm{Hf} / 177 \mathrm{Hf}, 142 \mathrm{Nd} / 144 \mathrm{Nd}, 204,206,207 \mathrm{~Pb} / 208 \mathrm{~Pb}, 87 \mathrm{Sr} / 86 \mathrm{Sr}$ $234 \mathrm{U}, 238 \mathrm{U}$, and $230 \mathrm{Th} / 234 \mathrm{U}$. The laser ablation device (NWR213) coupled to a QQQ ICP-MS is used to determine trace elements in solid materials. Three noble gas mass spectrometers are used in isotope hydrology: the Helix SFT is for low-level $3 \mathrm{H}$ analysis by the $3 \mathrm{He}$ ingrowth method, as well as for $3 \mathrm{H} / 3 \mathrm{He}$ age determination of young groundwater A VG5400 and a MM5400 mass spectrometer determine noble gas concentrations in groundwater to determine past recharge temperatures. Radiocarbon (14C) analysis in numerous research areas are performed with a MICADAS accelerator mass spectrometer dedicated for carbon isotopes. Cavity enhanced infrared laser spectrometers are in progress to measure oxygen and hydrogen stable isotope ratios of water samples (Los Gatos Research), as well as carbon isotope ratios of atmospheric $\mathrm{CH}_{4}$ and $\mathrm{CO}_{2}$ (Picarro). K/ $\mathrm{Ar}$ and $\mathrm{Ar} / \mathrm{Ar}$ dating are done by argon isotope mass spectrometers, including an ARGUS VI. A special low-lovel counter system has been just installed to determine 39Ar/Ar and 85Kr/ $\mathrm{Kr}$ ratios for dating groundwater in the range of 0 to 2000 years.

The facility is open for mutual research collaborations and analytical services, and aims to broaden and deepen the research fields of interests. The research results of ICER are published in highly ranked peer-reviewed journals, M.Sc. and Ph.D. theses. 


\section{DLab- Infrastructure for Fine and Structure Analysis}

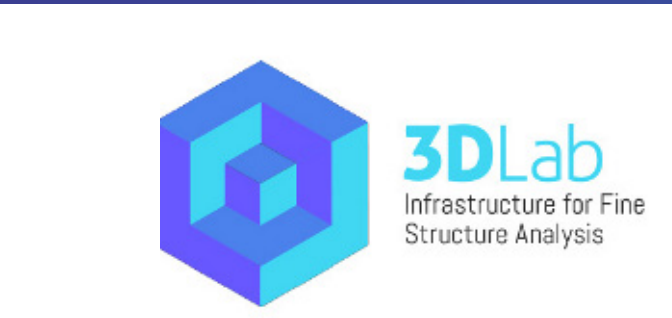

Host institution:

University of Miskolc

\section{RI location:}

Miskolc - Egyetemváros C/1 3515. Hungary

Status:

Fully operational, 2020-

\section{Partners:}

Robert Bosch Kft, ZF Hungária Kft, Infineon Technologies Cegléd Kft, Breuckmann GmbH \& Co KG, Thyssenkrupp, ATOMKI, Univ. of Debrecen, Budapest University of Technology and Economics

International connections:

J-resources

RIs: CERN

Research organizations: ESA, NHM-HAS, Partner in EU H2020 projetcs, Fraunhofer IFAM, ICAMCYL, LTSM, COMET

Available services:

ND residual stress, retained austenite measurements, 3D CT scan with metrology, 3D SEM, ODF, TEM lamella preparation, XRD scan, XRR SAX, up to $1200^{\circ} \mathrm{C}$

\section{Website:}

http://3dlabtest.uni-miskolc.hu/

\section{Person in charge:}

Prof. Dr. Valéria Mertinger,

head of the 3DLab, head of the Institute of Physical Metallurgy Metalforming and Nanotechnology

\section{Contact:}

mertinger.valeria@uni-miskolc.hu 3dlab@uni-miskolc.hu $+36-46-565-111 / 12-40$

\section{Description of the research infrastructure}

The 3DLab is an integrated laboratory for the provision of internationally competitive research, development, and innovation. The laboratory infrastructure and the related professional competences can provide complex answers to questions related to the spatial (3D) structure of materials. The subject of the tests can be metallic, mineral, organic or composite material. The dimensional order of magnitude can be in the range of nanometer to a meter from the area of basic research, raw material research, material and product development, manufacturing, failure or lifetime.

\section{Activities and services}

Stresstech XStress Robot is an advanced X-ray stress analyser. The goniometer attached to the robot arm with ability of fast repositioning to the various areas on the surfaces. Non-destructive residual stress and retained austenite measurements can be carried out on surfaces with great accuracy and without size and geometry limit. Depth profile measurements and non-destructive pole figure determination using our own patented method is also available.

YXLON FF35 Computer Tomograph is an instrument for characterizing the whole 3D structure of a materials. Due to the dual X-ray tube setup the bigger sample size at average resolution, and the smaller sample size at high resolution can be investigated. The observable materials have a broad range of size and material composition. It's not only for detection of cracks or voids in the material, but with the metrology function, the whole geometry is reconstructable and quantifiable in $3 \mathrm{D}$, with high resolution.

Thermo Scientific Helios G4 PFIB CXe Scanning Electron Microscope with Correlative Laser Cutting is capable of up to $0.6 \mathrm{~nm}$ resolution. The correlative laser cutting and inductively coupled Xe-plasma can process big volumes and surfaces of materials. The precisely focused plasma beam can cut $3 \mathrm{~nm}$ thin slices, so high resolution 3D chemical element maps and EBSD maps can also be constructed. TEM grids can be studied in STEM scanning transmission mode for dark field, bright field and chemical composition analyses. The Bruker D8 Discovery multipurpose Xray diffractometer with unique X-ray optical and geometry solutions, such as the Da-Vinci control, a push-plug automatic parts recognition, parallel beam and Bragg-Brentano geometry, capillary sample holder and motorized stage allows the investigation of samples with various sizes and amounts. The energy dispersive position sensitive detector opens a new dimension in data acquisition and measurement dynamics. The other unique attachment is a heating stage with $1200^{\circ} \mathrm{C}$, thus fast thermal transformations are observable in inert gas or vacuum. The instrument has small angle $X$-ray scattering (SAXS) and X-ray reflectometry (XRR) capabilities. For the low- and small angle measurements a software controlled motorized air scatter screen is also available.
NATIONAL RESEARCH, DEVELOPMENT AND INNOVATION OFFICE HUNGARY 


\section{International territorial water management and climate adaptation instruments centre}

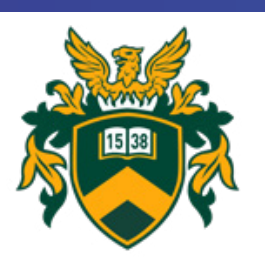

UNIVERSITY of

DEBRECEN

Host institution:

University of Debrecen, Institute

of Water and Environmental

Management

RI location:

4032 Debrecen,

Böszörményi u.138., Hungary

Status:

Partially operational, 2020-

International connections: RIs: Ain Shams University, Mansoura University.
Slovak University of Agriculture in Nitra, University of Oradea Global Water Partnership Central Eastern Europe

Research organizations: CABI, DHI, Partners in EU projects (H2O2O currently: WATERAGRI)

Available services:

Researches in the fields of agriculture, water management and environmental sciences.

\section{Website:}

https://mek.unideb.hu/node/233

\section{Person in charge:}

János Tamás, Head of Institute

Contact:

tamas@agr.unideb.hu

watershed monitoring devices; field drainage planning equipment; devices gauging geophysical and hydrological properties of soil; hydrological and hydraulic model tools; special research equipment of agricultural water management and irrigation technology: erosion control and land reclamation laboratory equipment; irrigation water quality protection devices and equipment for data-processing. The IT network supports the computerized data processing, water management planning and decision-making, the data collection system of the entire unit, and the data acquisition by ground water monitoring wells in the TransTisza monitoring areas. The irrigation technology, soil and water quality protection instruments, the related control units and the soil-plant systems used for holistic measurement purposes and characterising hydrological parameters are placed in the greenhouse. The power demand of the greenhouse and the local equipment is met by a sustainable solar energy power system.

\section{Activities and services}

Activities and services became available in the framework of the project such as experimental and demonstration tools for hydrological and hydraulic researches; soil, water, weather and plant water balance; groundwater monitoring system; high resolution precipitation monitoring; researches on precision irrigation technology. The unique infrastructure further enhances the multidisciplinary educational and research activities of the University of Debrecen in the transboundary river basin of the Tisza River. The infrastructure serves the implementation of a Horizon 2020 project: the WATERAGRI. The WATERAGRI project is about researching the new frontiers in integrated water resources management of small agricultural catchments to improve both European agricultural production and the status of local ecosystems. The WATERAGRI consortium consists of a group of 23 partners from 12 European countries. The infrastructure implemented in the project is connected to the institution's researcher bases with the domestic and international research network in the fields of agriculture, water management and environmental sciences.

and surfaces of materials. The precisely focused plasma beam can cut $3 \mathrm{~nm}$ thin slices, so high resolution 3D chemical element maps and EBSD maps can also be constructed. TEM grids can be studied in STEM scanning transmission mode for dark field, bright field and chemical composition analyses.

The Bruker D8 Discovery multipurpose Xray diffractometer with unique X-ray optical and geometry solutions, such as the Da-Vinci control, a push-plug automatic parts recognition, parallel beam and Bragg-Brentano geometry, capillary sample holder and motorized stage allows the investigation of samples with various sizes and amounts. The energy dispersive position sensitive detector opens a new dimension in data acquisition and measurement dynamics. The other unique attachment is a heating stage with $1200^{\circ} \mathrm{C}$, thus fast thermal transformations are observable in inert gas or vacuum. The instrument has small angle X-ray scattering (SAXS) and X-ray reflectometry (XRR) capabilities. For the low- and small angle measurements a software controlled motorized air scatter screen is also available. The International River Basin Management and Climate Adaptation Centre is launched The Centre is a state of the art research facility in Hungary and Central Europe in the agricultural water management discipline. The climate adaptation solutions to be developed here is brought significant breakthrough in addressing drought, inland waters and urban hydrology. The complex infrastructure is a unique system with two interconnected parts: hydrological measurement facilities and the controlled greenhouse research. The "agricultural" campus of the University of Debrecen is an ideal place for training, research and professional consulting. Instruments installed here include:

NATIONAL RESEARCH, DEVELOPMENT AND INNOVATION OFFICE HUNGARY 


\section{Bioanalytical instrumentation for analyte examination at molecular and cellular levels}

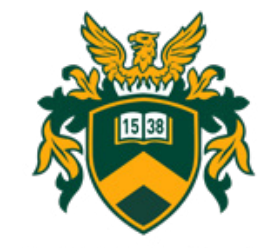

\section{UNIVERSITY of}

Host institution:

Faculty of Medicine, University of

Debrecen

RI location:

Debrecen, Nagyerdei campus

Status:

Fully operational

Partners:

University of Szeged, University of

Pécs, Semmelweis University

International connections:

RIs:

University of Siena, Italy,

University of North Texas

USA

Research organizations:

European Biolmaging node

ELIXIR Proteomics
Available services:

protein identification, post-

translational modification detection,

label-based and label-free mass

spectrometry-based quantification,

intact protein examination

metabolite identification, amino acid

analysis, detection of biomolecular

interactions, high speed confocal

microscopy scanning, HTS screening

\section{Website:}

https:// kancellaria.palyazatok

unideb.hu/en/bioanalytical-

instrumentation

\section{Person in charge:}

Prof. József Tözserr, vice-rector of the University of Debrecen, tozser@med. unideb.hu

Contact:

Dr. Éva Csösz,

cseva@med.unideb.hu

\section{Description of the research infrastructure}

The research infrastructure acquired with the help of the GINOP-2.3.4-15-2016-00002 is hosted by various departments of the Faculty of Medicine and is embedded into the Core Facility framework of the University of Debrecen. The instrument systems fit into the instrumentation of the different, already existing core facilities, ensuring in this way the high standards of scientific excellence. The long years of expertise of the core facility staff, the highly collaborative working environment and the stable operational framework provided by the University of Debrecen make these core facilities good partners in any R\&D type projects.

\section{Activities and services}

The high precision and high speed Orbitrap Tribrid mass spectrometry system equipped with ESI and nano ESI ion sources, ETD, HCD and CID collision techniques, provides a large spectrum of analytical possibilities for the examination of proteins and small molecules present in biological samples even at femtomolar levels. The mass spectrometer along with the Transcend ${ }^{\mathrm{TM}} \mathrm{II}$ TurboFlow ${ }^{\mathrm{TM}}$ system is part of the Proteomics Core Facility hosted by Department of Biochemistry and Molecular Biology and allows for the rapid online sample preparation and analysis. The instrumentation along with performant software make possible the identification and quantification of various compounds present in complex matrixes. The Monolith NT instruments series, including NT.115 LabelFree and NT.115 Red/ Blue devices, are based on the phenomenon of microscale thermophoresis (MST) and they provide broad applications for detection of interactions in the range of $\mathrm{pM}$ to $\mathrm{mM}$ binding affinities between many types of biomolecules. The MST based instruments are excellent additions to other equipment (Biacore3000, ITC200) used in the Biomolecular Interaction Core Facility hosted by the Department of Medical Chemistry to determine molecular interactions based on surface plasmon resonance (SPR) and isothermal titration calorimetry (ITC). The ZEISS LSM 880 AiryScan being part of the Functional Imaging Laboratory, Department of Physiology, allows the users to investigate large fields of view with high speed scanning confocal microscope at an unsurpassed image quality. It is designed for optimized productivity to investigate subcellular structures at a new level of detail. The system provides the speed to monitor molecules and their interactions in space and time while minimizing the input of light. The EnVision 2105 Multiplate reader situated in the Department of Immunology is a HTS-screening system providing exceptional speed and maximum sensitivity across a wide spectrum of detection technologies. These include fluorescence, ultra-sensitive luminescence, absorbance, time-resolved fluorescence and TR-FRET methods, as well as AlphaScreen $₫$, and AlphaLISA $₫$ technologies, which offer unparalleled sensitivity and precision in the detection of both intracellular processes and secreted factors. 


\section{HEALTH \& FOOD}

\section{Biolmaging Hungary}

\section{EURO- BIOIMAGING}

\section{Host institution:}

University of Debrecen, coordinator

\section{RI location:}

University of Debrecen

Semmelweis University, Budapest

Biological Research Centre, Szeged

Femtonics Ltd., Budapest

Status:

Operational since 2010

Partners:

University of Pécs,

Institute for Nuclear Research

(Atomki),

Scanomed Ltd.,

MEDICOPUS Health Service

Nonprofit Ltd. Kaposvár,

Institute of Experimental

Medicine Budapest
International connections: Euro-Biolmaging (EuBI) ERIC

RIs:

Cellular Imaging Hungary, EuBI Node

Available services

Advanced light and electron

microscopy Preclinical and medical

imaging

Website:

https://www.eurobioimaging.eu

Person in charge:

János Szöllösi, EuBI board member szollo@med.unideb.hu

Contact:

György Vámosi, EuBI board member

vamosig@med.unideb.hu

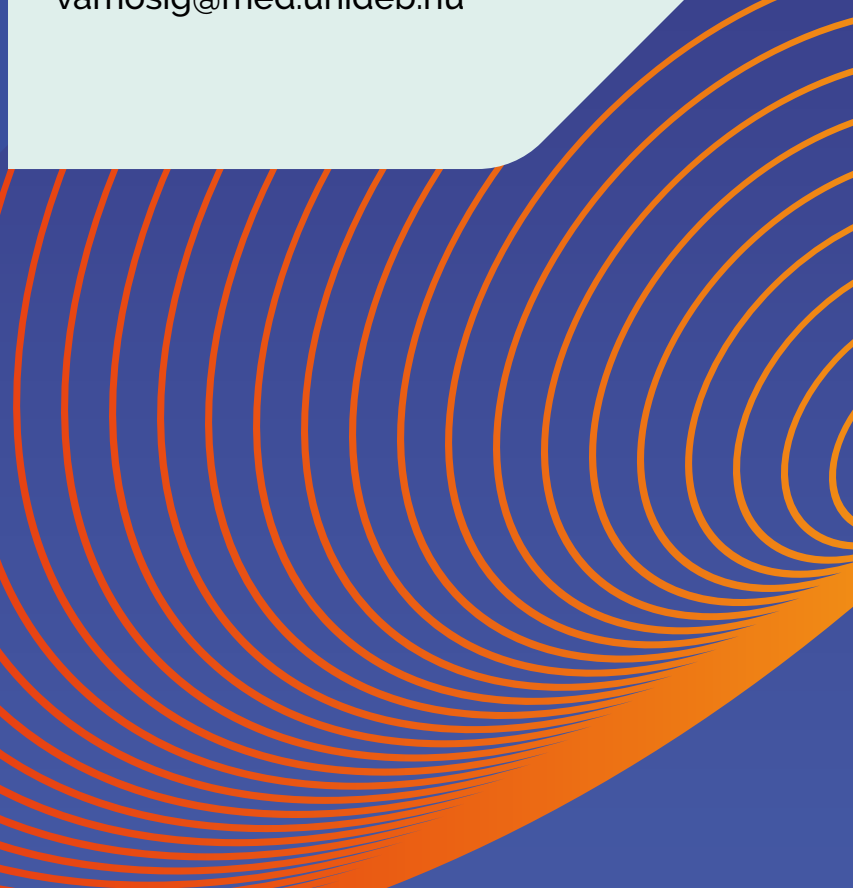

Hungary's membership in European

research infrastructures

\section{Description of the research infrastructure}

Modern light microscopy and medical imaging play an increasing role in basic and applied biomedical research and diagnostics. Euro-Biolmaging (EuBI) (www.eurobioimaging.eu) was set up in 2010 under the auspices of European light microscopy and medical imaging microscopy laboratories to operate as an ESFRI ERIC, which was legally formed in 2019 , with Hungary among its 14 founding members. The aim of EuBI is to serve life scientists with state-of-the-art imaging techniques ranging from microscopy to medical imaging throughout Europe. In 2009, the Hungarian Biolmaging Network was established. Several member labs at the Univ. of Debrecen, Biological Research Centre, Szeged, Semmelweis University and Femtonics Ltd., Budapest formed the "Cellular Imaging Hungary" EuBI Node after a successful Node application. In 2020, the University of Pécs is submitting an application to join the Node as well. A second application is submitted to form the "Medica and Preclinical Imaging Hungary" Node with the participation of the University of Debrecen Institute for Nuclear Research (Atomki), Scanomed Ltd., Semmelweis University Budapest, University of Pécs and MEDICOPUS Health Service Nonprofit Ltd. Kaposvár.

\section{Activities and services}

The Cellular Imaging Hungary EuBI Node and its partner labs have been upgraded in recent years with the help of EU and governmental grants to reach state-of-theart in several imaging technologies. Cutting-edge techniques are also developed and manufactured at these labs. A non-exhaustive list of techniques serving academic and industrial users at the infrastructures includes: super-resolution microscopies (stimulated emission depletion, photoactivated localization, stochastic optical reconstruction, structured illumination), 2D and 3D fast multi-photon laser scanning microscopy; Förster resonance energy transfer; fluorescence lifetime imaging; fluorescence (cross)correlation spectroscopy; differential polarization laser scanning microscopy; Rescan confocal microscopy; optical tweezers; atomic force microscopy; stimulated Raman spectroscopy; high throughput microscopy and automated image analysis, single cell laser dissection; correlative light and electron microscopy; serial block-face scanning electron microscopy; functional medical imaging equipment (CT, PET/CT, MRI, SPECT, fMRI, NEXSTIM); imaging equipment for preclinical, translational research (e.g. mini-PET, nano-PET/CT, PET/MRI, fMRI, micro-CT, bioluminescent imager).

wide spectrum of detection technologies. These include fluorescence, ultra-sensitive luminescence, absorbance, time-resolved fluorescence and TR-FRET methods, as well as AlphaScreen $\AA$, and AlphaLISA $₫$ technologies, which offer unparalleled sensitivity and precision in the detection of both intracellular processes and secreted factors.

NATIONAL RESEARCH, DEVELOPMENT AND INNOVATION OFFICE HUNGARY 


\section{Biosafety Level-4 Laboratory at University of Pécs (BSL-4)}

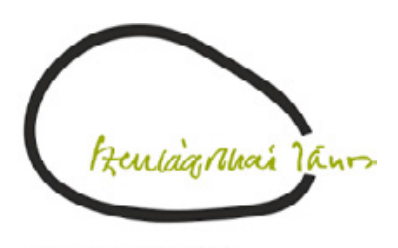

UNIVERSITY OF PÉCS

SZENTAGOTHAI RESEARCH CENTRE

Host institution:

University of Pécs, Szentágothai Research Centre (UP-SRC)

\section{RI location:}

Pécs, University Campus

\section{Status:}

Fully operational, 2017-

\section{Partners:}

Mostly universities and other academic research institutes

\section{International connections:}

RIs:

University of Kent, NIAID,

USAMRIID, University of Boston,

Vietnam Academy of Sciences and

Technology, PHE

Research organizations:

ERINHA, Partners in EU projects

(H2O2O), COST Action
Available services:

Traditional virological

microbiological (tissue culture

virus isolation), molecular

biological (recombinant DNA

techniques, protein expression)

and immunological (ELISA, WB, IF

staining) techniques are available.

Website:

https://szkk.pte.hu/

\section{Person in charge:}

Prof. Dr. Jakab Ferenc, Scientific

Director of UP-SRC, jakab.ferenc@

pte.hu

\section{Contact:}

Prof. Dr. Jakab Ferenc

Leader of BSL-4 Laboratory,

jakab.ferenc@pte.hu

\section{Description of the research infrastructure}

The Szentágothai Research Centre of the University of Pécs is a new research institute established on the basis of modern international science organizational and management normatives. It covers all aspects of education, research and innovation in the fields of biomedical, natural and environmental sciences. The infrastructure and all the wellequipped laboratories provide an excellent basis to become a well-known, leading research facility in Hungary, as well as in Central Europe with an extensive, fruitful national and international collaboration network.

The BSL-4 virological laboratory is well-equipped, designed properly and meets the requirements of the laboratory protocol declared by the CDC-BMBL (5th edition), ensuring the safe working conditions with highly infectious materials. The BSL-4 laboratory has official certificates for Occupational Health and Safety Management System (OHSAS 18001:2007) also. Besides the BSL-4 facility, the research group has an already suitably running molecular virological laboratory which provides all the necessary instruments. In 2020 , the laboratory was officially assigned as the National Laboratory of Virology, which is primarily responsible for virological research activities in Hungary.

\section{Activities and services}

The main profile of the group is the research of viral zoonoses (diseases that are spread from animals to humans caused by viruses). Due to global warming and the expansion of human living-space, animal viruses pose a growing threat for human - and veterinary health. Pathogens causing severe epidemics are emerging more frequently due to global activities. One of the aims of our research is to identify well known and new pathogens in samples originating from Hungary and from abroad through our extensive international collaboration network. Studies intend to monitor their prevalence, characterize their genetic background and describe the mechanism of viral infection. Viruses carried by rodents, bats, mosquitoes and ticks are studied primarily. We have established well-functioning collaborations with stakeholders in public health, animal health and industry, and we also contribute to the development of diverse diagnostic methods for the pathogens characterized in the laboratory. In addition to basic research, we are conducting important research in the development of antiviral drugs, as well as there is possibility of vaccine development projects, both primarily for highly infectious viruses.
NATIONAL RESEARCH, DEVELOPMENT AND INNOVATION OFFICE HUNGARY 


\section{European Life-sciences Infrastructure for Biological Information}

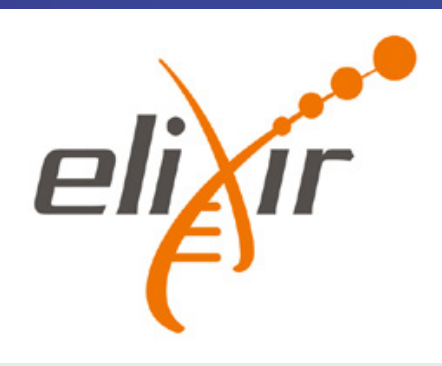

Host institution:

Research Centre for Natural

Sciences, Institute of Enzymology

RI location:

Budapest 1117, Magyar Tudósok körútja 2.

\section{Status:}

Fully operational, 2019-

Partners:

University of Debrecen, University of Pécs, Semmelweis University, Eötvör Lóránd University, Centre for Ecological Research, Institute for Veterinary Research, National Institute of Oncology, University of Veterinary Medicine Budapest, Biology Research Centre Szeged Rényi Institute, National Agriculture Research and Innovation Centre

International connections:

ELIXIR partner institutes including Swiss Institute of

Bioinformatics,
RIs:

ELIXIR

Available services:

CCTOP, HMMTOP, TMDET,

TmFoldWeb, IUPred, KM-plotter,

ANCHOR, IsoMut, Kooplex, MÉTA

G-2-O, Recurrence Online, ROC

plotter, HTP, TOPDOM, TOPDB,

TSTMP, PDBTM, National Cancer

Registry, GALAXY

Website:

http://www.elixir-hungary.org/

Person in charge:

gyorffy.balazs@ttk.hu

Contact:

Csilla Kocsis-Szalkai

kocsis-szalkai.csilla@med.

semmelweis-univ.hu
Dr. Balázs Györffy, Head of Node,

\section{Description of the research infrastructure}

Bioinformatics comprises the computationally supported analysis of life science data employing algorithms, programs, and databases. Worldwide, Hungary is among the 40 most advanced countries in this new field. ELIXIR is a research infrastructure which organizes the bioinformatic resources available at the partner institutes into a single network.

\section{Activities and services}

We work in three major directions:

By establishing communities we focus on pre-set scientific topics.

Such projects include rare diseases, 3D bioinformatics, human copy number variation, intrinsically disordered proteins and many more.

We put great emphasis on the teaching of bioinformatics. Since this is a relatively new field of science, knowledge is almost non-existing. We organize curses across the country and also enable members to invite international teachers to boost teaching capacity. Primary focus is on PhD fellows, but gradual students are also targeted. We establish and maintain services necessary to execute bioinformatic data analysis. These include online services many of which are world-leading (including CCTOP, HMMTOP, ANCHOR, KM-plotter, ROC-plotter) as well as data processing platforms (GALAXY) and data repositories (Hungarian EGA server).

Leading scientific topics include oncology (seven active ELIXIR research groups), COVID-19 research (three active ELIXIR research groups) and protein structure (four active research groups).

A major future goal of the Hungarian Node is to establish a framework for the country-wide bioinformatic data processing of medical omics data.
NATIONAL RESEARCH, DEVELOPMENT AND INNOVATION OFFICE HUNGARY 


\section{Hungarian European Clinical Research Infrastructura Network (HECRIN)}

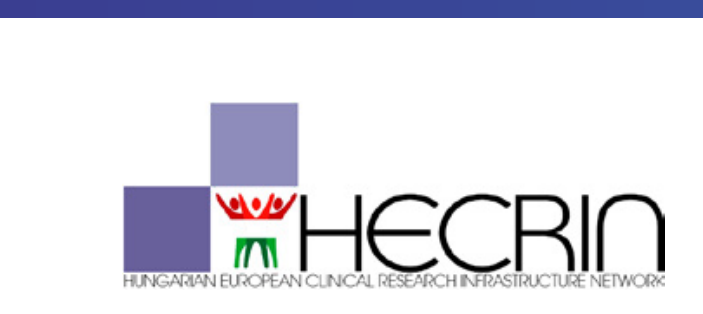

Host institution:

University of Pécs (UP), Szentágothai Research Centre

\section{RI location:}

Pécs

\section{Status:}

Distributed infrastructure, 2014-

\section{Partners:}

University of Szeged, Semmelweis University, University of Debrecen, National Institute of Oncology, State Hospital for Cardiology, National Institute of Rheumatology and Physiotherapy, National Institute of Clinical Neurosciences, Gottsegen György Hungarian Institute of Cardiology, Korányi National Institute of Pulmonology, Heim Pál Children's Hospital, MCRN Hungary (Medicine for Children Research Network), Hungarian Academy of Sciences - Research Centre for Natural Sciences Brain Imaging Centre,
HunPedNet (Hungarian Pediatric Pharmahungary 2000 Ltd., National Institute of Pharmacy and Nutrition

\section{International connections:} ECRIN-ERIC

Research organizations: clinical trial units (CTUs) of HECRIN member institutions

Available services:

management of clinical trials, education

\section{Website:}

https://hecrin.pte.hu, https://szkk pte.hu

Person in charge:

Prof. Dr. Gábor L. Kovács,

kovacs.l.gabor@pte.hu

Contact:

Dr. Zita Tarjányi, European

Correspondent

tarjanyi.zita@pte.hu Network), AdWare Research Ltd.

\section{Description of the research infrastructure}

The European Clinical Research Infrastructure Network (ECRIN-ERIC) is a landmark nonprofit organization included in the ESFRI Roadmap to support non-commercial, sciencebased, multicentric pharmaceutical research in Europe. In 2014, the Hungarian member organization - the HECRIN Consortium - became a full member of ECRIN-ERIC. HECRIN Consortium is the scientific partner, the national hub of ECRIN-ERIC in Hungary with the goal to provide support to national investigators seeking to internationalize clinical trials, and to involve their country in clinical trials initiated by investigators in other European countries. The results of human clinical trials have a significant impact on the development of clinical medicine.

\section{Activities and services}

As a full member of ECRIN, the HECRIN consortium strives to harmonize European clinical research through a wide range of services (database management, partner search, reference validation, education). Through this partnership, and various international and national grants, HECRIN coordinates high-quality, independent and fully transparent multinational academic (investigator-initiated) clinical trials, enhancing the capabilities of the national clinical research infrastructure.

The European network is based on the connection of national networks of Clinical Trials Units (CTU). CTUs are specialised biomedical research units which design, centrally coordinate and manage clinical trials, prognostic, diagnostic studies, and meta-analyses, deal with the design of the study, its organisation, logistics, centre selection, data management, monitoring, data analysis, pharmacovigilance and reporting. HECRIN developed a high quality, integrated clinical trial network at all four university-based clinical research facilities in Hungary and one for pediatric research, which allows to enhance Hungary's capacity for conducting innovative, high quality clinical research involving pharmaceuticals, nutriceuticals or clinical care pathways, as well as clinical investigation of medical devices.

In addition, the Consortium promotes the continuous professional training of the study team and the supporters, as well as it strives with special efforts for the utilization of clinical data assets for research purposes.

During the COVID-19 pandemic HECRIN Consortium has become the main partner of the Hungarian Ministry of Innovation and Technology in the field of governmentsponsored anti-Covid trials.a 


\section{Integrated Infrastructure for Molecular Science and Molecular Medicine (I2M2)}

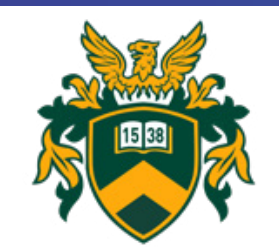

UNIVERSITY of DEBRECEN

Host institution

Institute of Chemistry,

University of Debrecen

RI location:

Debrecen, University of Debrecen

Chemistry Campus

Status:

Fully operational, 2018-

International connections: Karlsruhe Institute of Technology: Institut Pasteur de Lille; Institut Pasteur de Montevideo; Bizkaia Science and Technology Park, Derio; Griffith University; Technische Universität Darmstadt; University of Manchester; Division of Molecular Biology, Innsbruck Medical University

International connections: Research organizations: Partners in EU projects (EAST NMR, INSTRUCT, Bio- NMR, COST, iNEXT)
Available services:

NMR, CE-MS and X-ray diffraction measurements

\section{Website:}

http://i2m2.unideb.hu/index.php http://i2m2.unideb.hu/index_en.php https://debnmr.unideb.hu/en

Persons in charge:

Heads of NMR facility

Prof. Katalin E. Kövér,

kover@science.unideb.hu

Prof. Gyula Batta

batta@unideb.hu

Heads of CE-MS facility

Prof. Attila Gáspár,

gaspar@science.unideb.hu

Prof. Sándor Kéki,

keki.sandor@science.unideb.hu

Head of X-ray facility

Dr. Attila Bényei,

abenyei@unideb.hu

Contact:

Prof. Katalin E. Kövér,

kover@science.unideb.hu

\section{Description of the research infrastructure}

The Integrated Infrastructure Center established in 2018 at the University of Debrecen within the frame of I2M2 project (GINOP-2.3.3-15-2016-00004 financed by European Regional Development Fund) serves as a core facility in support of advanced multidisciplinary research in the field of molecular and life sciences, including structural chemistry, structural biology, pharmaceutical, food and environmental research. The stateof-the-art instruments installed in the Infrastructure Center extend the scope of academic and innovation research activities in progress currently or in the future and provide indispensable links between academic and industrial research at national and international level, enhancing visibility of the University of Debrecen in the European Research Area.

\section{Activities and services}

The Bruker Avance NEO $700 \mathrm{MHz}$ NMR spectrometer equipped with Prodigy TCl cryoprobe offers outstanding sensitivity and resolution, supporting research activities in diverse areas. The NMR facility (DEBNMR) also operating three other spectrometers (Bruker 360 , 400,500 ) offers a wide range of high resolution, multinuclear and multidimensional NMR measurements for structure determination and dynamics study of carbohydrates, peptides, proteins and other synthetic and natural products. The research team has special expertise in method development for sensitive and reliable measurement of important NMR parameters.

The mass spectrometer (maXis II (Bruker)) equipped with quadrupole technology in conjunction with a time-of-flight analyser (ESI-QTOF-MS) is one of the highest resolution and most sensitive mass spectrometers being available in the market, allowing determination of accurate molecular masses and structures of small to large (bio) molecules. The hyphenation with capillary electrophoresis (7100 Agilent)(CE) provides a high performance analytical instrumentation for the analysis of biological samples.

The Bruker D8 Venture X-ray diffractometer equipped with high brilliance dual microsource ( $\mathrm{Cu}$ and Mo), high sensitivity detector and low temperature unit allows to measure crystal samples between 90 and 500K. Crystal and molecular structures of small molecules, metal complexes or even proteins can be determined. With the present configuration of the equipment powder diffraction measurements are also feasible. 


\section{^ HEALTH \& FOOD}

\section{Biobank Network}

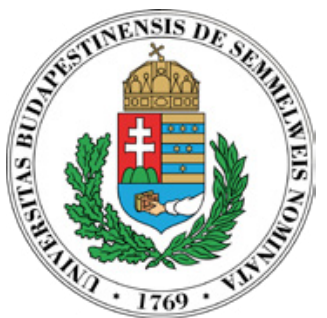

Host institution:

Semmelweis University, Budapest

RI location:

Semmelweis University Campus

Status:

Fully operational

Partners: for Molecular Fingerprinting, Oncompass Medicine Ltd.

International connections: Research organizations: RIs:

BBMRI European Reference Network
Gedeon Richter Plc., Center

\section{Website:}

www.semmelweis.hu

\section{Person in charge:}

Prof. Dr. Mária Judit Molnár, Director of Institute, Genomic Medicine and Rare Disorders

\section{Contact:}

András Fodor, Project Manager

Genomic Medicine and Rare Disorders fodor.andras@med.semmelweis-univ.hu

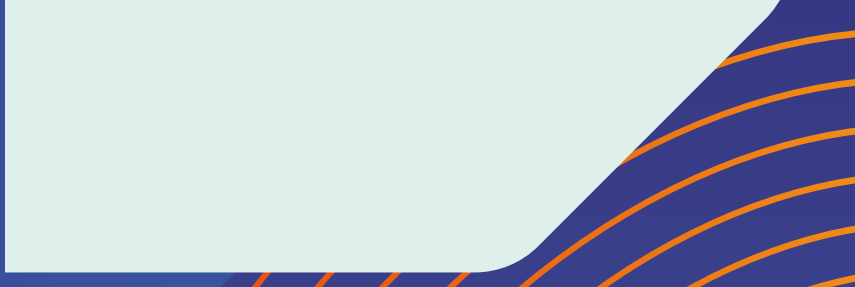

\section{Description of the research infrastructure}

Semmelweis University has been one of the leading biomedical institutions of higher education in Hungary and Central Europe for the last 250 years. The University today is handling 2.5 million patient visits each year within nearly 40 departments. Research, and social sciences. Within these, life science R\&D\&I activities are the most prominent. The R\&D\&I results quickly make their way into clinical and health sciences as well as into the University's educational activities and the curriculum. The synergies also manifest themselves in the various specialized networks operating at the University (e.g. nanotechnology, bio-imaging, genomics, biobank), as well as in the research university modules (diagnostics, technology, therapy, prevention) and the dynamic collaborations which have been developing within these areas. The Semmelweis Biobank Network was established in 2010 with the goal of efficiently using the synergies that occur in patient care, education, research/development and a wide spectrum of health care areas all under University premises.

\section{Activities and services}

The Biobank Network at Semmelweis University consists of 14 institutes and 15 biobanks. The aggregate sample size for these institutes currently stands at 87000 , registering over 10000 new samples in 2019. Sample types vary from DNA, skin, nerve to muscle and other biopsy tissues. Areas covered by the Biobank Network include: cardiology, neurology, psychiatry, hematology, nephrology, rheumatology, ophthalmology, endocrinology, dermatology. The University has a Rare Disease network with large biobank.

Samples from the Semmelweis Biobank Network have been used in over 60 research projects during the networks existence. A main strategic goal for Semmelweis University is to enhance the role of the Biobank Network both internally and externally. A key element in achieving this goal is our application to the Biobanking and BioMolecular Resources Research Infrastructure (BBMRI). The University is also in pursuit of offering commercialized services based on the Biobank Network, tightening the relationship with other players from the biobanking field such as industry, biobankers and other private sector parties. The currently running initiatives are all in the hope of making significant contributions to biomedical research and to the evolution of new treatment methods. development, and innovation (R\&D\&I) take place in the areas of living natural sciences,

\section{NATIONAL RESEARCH, DEVELOPMENT AND INNOVATION OFFICE HUNGARY}




\section{PHYSICAL SCIENCES \& ENGINEERING}

\section{Autonomous Vehicles Research Centre (AVRC)}

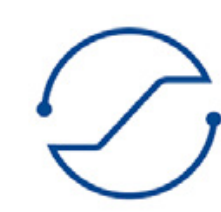

\section{SZTAKI}

\section{Host institution:}

Institute for Computer Science and

Control (SZTAKI), Eötvös Loránd

Research Network

\section{RI location:}

Budapest

Status:

Status: Fully operational, 2015-

Partners:

BME, SZE, ZalaZONE

Research organizations: TUM Uni. of Minnesota, SUPAERO,

TU Delft, TU Eindhoven

\section{Available services:}

Autonomous test vehicles (road and airborne), custom sensor and actuator development, sensor fusion, virtual simulation environment, model based system development and testing

Website:

https://wwww.sztaki.hu/

Person in charge:

Péter Gáspár

gaspar@sztaki.hu

Contact:

Bálint Vanek

vanek@sztaki.hu

Alexandros Soumelidis

soumelidis@sztaki.hu

versatile test environments for supporting research activities of vehicle control. One
of the test platforms is an electric passenger car equipped with computer-controlled functions. Multiple on-board embedded systems as well as multiple sensors serve as the base or performing experiments in a wide range of automated control problems.

The experimental system is coupled with a model-based system design and simulation environment consisting of commercial development tools as well as custom developed reusable prototype components, serving the needs of the theoretical and experimental work. An excellent opportunity to realize tests and experiments by this platform is provided by ZalaZone automotive test field. Under the framework of the Technological Centre established in the test field SZTAKI and Széchenyi University maintains a laboratory that allows for efficient on-site work. Most of the key sensing and control equipment are also used onboard the Sindy unmanned aerial vehicle research platform. Key technologies, like inertial and navigation satellite based sensor fusion, or vision based navigation are tested on both ground and airborne platforms. Coupled with the vehicles the institute also hosts an extensive hardware-in-the-loop test environment, where novel safety critical software components can be tested on the actual hardware before implementing them onboard the vehicles.

\section{Activities and services}

The experimental vehicle control platforms provide cooperation possibilities in the validation and testing of new methods and algorithms. Experimental verification of concepts improves acceptability of the results by the scientific and technological community. Beyond the benefits to partners the experimental platform offers opportunity for cooperation with other research institutes, and universities, as well as with industrial partners in the field of autonomous systems. SZTAKI is open to participate in joint research and development activities, national and international competitions and tenders. The unique experimental platforms can also be involved in the university education, and provides the opportunity to realize university student programs.

Clinical Trials Units (CTU). CTUs are specialised biomedical research units which design, centrally coordinate and manage clinical trials, prognostic, diagnostic studies, and metaanalyses, deal with the design of the study, its organisation, logistics, centre selection, data management, monitoring, data analysis, pharmacovigilance and reporting. HECRIN developed a high quality, integrated clinical trial network at all four university-based clinical research facilities in Hungary and one for pediatric research, which allows to enhance Hungary's capacity for conducting innovative, high quality clinical research involving pharmaceuticals, nutriceuticals or clinical care pathways, as well as clinical investigation of medical devices.

In addition, the Consortium promotes the continuous professional training of the study team and the supporters, as well as it strives with special efforts for the utilization of clinical data assets for research purposes.

NATIONAL RESEARCH, DEVELOPMENT AND INNOVATION OFFICE HUNGARY 


\section{PHYSICAL SCIENCES \& ENGINEERING}

\section{Cyber Physical Pilot Production System}

\section{IPAR 4,0}

Host institution:

Institute for Computer Science and Control (SZTAKI)

\section{RI location:}

Budapest SZTAKI campus, Györ, Széchenyi University Campus

Status:

Status: Fully operational, 2018-

\section{Partners:}

Budapest University of Technology and Economics, Széchenyi University in Györ,

International connections / Research organizations: Fraunhofer Austria

\section{Research Infrastructures}

\section{Description of the research infrastructure}

The Research Laboratory on Engineering and Management Intelligence (EMI) at the Institute for Computer Science and Control (SZTAKI) has built up two learning factory facilities in Budapest and Györ, providing an infrastructural background for experiments and hands-on experience in various aspects of cyber-physical production systems (CPPS). The facility in Budapest, named "Smart Factory", is a compact, high-level but functional representation of an entire production site, occupying an area of ca. $30 \mathrm{mz}$. While no actual production process is taking place, re-usable workpieces still undergo physical handling representative of processes in a production plant. The learning factory site established at the premises of Széchenyi University in Györ focuses on collaborative processes on the shop-floor level, with several workstations set in a common open space of ca. $75 \mathrm{m2}$. The workstations comprise a central element with one or more collaborative robots, and a set of configurable table extensions where assembly and auxiliary operations can take place. The structure of the workstations is designed for collaborative involvement of humans and robotic resources in assembly processes, with many of the physical resources being equally accessible to human and robotic handling. The workstations have an open spatial arrangement, blending into the shop-floor area without fixed boundaries, representing one of the possible future factory layout concepts. Most operations are conceived to leave the choice open for using robots or human workforce, and, similarly, material streams between workstations can equally be served by humans or automated guided vehicles (AGVs).

\section{Activities and services}

Both learning factory facilities retain substantial flexibility and evolvability in their composition, enabling both the processes themselves and the underlying automation infrastructure to be subject to education, training, research and development. The learning factories have already been host to training and education activities, and the development of a harmonized didactic portfolio is ongoing. In this regard, two tracks are followed. An industrial track is built around services for industrial enterprises, integrating customized demonstrations and risk-free experiments with new technologies, as well as training and knowledge transfer programs for employees of the enterprises. The developed framework supports the modeling, planning and execution control of processes in cyber-physical production systems, enabling process transparency, virtual representation and accessibility of physical components for observation and control in a structured approach. In parallel, an academic track comprises participation in higher education via individual student projects (e.g., leading up to BSc, MSc or PhD theses), and a project-oriented course for elaborating mechatronics solutions.for the utilization of clinical data assets for research purposes.
NATIONAL RESEARCH, DEVELOPMENT AND INNOVATION OFFICE HUNGARY 


\section{PHYSICAL SCIENCES \& ENGINEERING}

\section{Extreme Light Infrastructure Attosecond Light Pulse Source (ELI-ALPS)}

\section{(1)1) eli}

attosecond

Host institution:

ELI-HU Non-Profit Ltd (project company)

RI location:

Szeged, Hungary

\section{Status:}

Partial operation, full operation expected from 2023

\section{Partners:}

In the ELI project ELI-ALPS is partnered with ELI BL (Prague) and ELI NP (Bucharest). In national projects the Wigner Research Centre, the University of Szeged, ATOMKI, the Szeged based Biological Research Centre and the University of Pécs are collaborating partners. Implementation is ensured through international partnerships.

International connections: ELI-HU is a member of the HEPTech Network, and a founding member of the future ELI ERIC.

\section{Description of the research infrastructure}

ELI is the first laser based user facility in the world where light-matter interactions can be studied at the highest intensities to date, in the so-called ultrarelativistic range at the fastest time scales from femto- to attoseconds. It is also the first civilian large-scale, high-power laser research facility to be realized with trans-European cooperation and the involvement of a global scientific community within the ELI project. With coordinated management and research strategies, Hungary, the Czech Republic and Romania are simultaneously working towards the full-scale implementation of the project through the construction of three laser facilities, representing the three pillars of the distributed research infrastructure with respective missions in attosecond, particle acceleration and photonuclear applications.

The main objective of ELI-ALPS, the Hungarian pillar of the Extreme Light Infrastructure, is the establishment of a unique research facility which provides ultrashort (few-cycle), highrepetition-rate light pulses in the frequency range between $\mathrm{THz}(1012 \mathrm{~Hz})$ and X-ray (1018$1019 \mathrm{~Hz}$ ) for developers and end-users.

\section{Activities and services}

ELI-ALPS is dedicated to support fundamental and applied research in physical, biological, chemical, medical and materials sciences at extreme short time scales. The state-of-theart laser systems and the subsequent outstanding secondary sources generate the highest possible peak powers at the highest possible repetition rate in a wide spectral domain in the form of few- to single-cycle pulses. The facility - with highly trained scientific staff aims to provide access to its research infrastructure for user groups from all around the world. As the first systems are already online, ELI-ALPS has opened a commissioning user programme, where the range of available equipment is continuously growing.

\section{The main research fields and applications at ELI-ALPS include:}

Gábor Szabó

Managing Director of ELI-HU,

Gabor.Szabo@eli-alps.hu

Contact:

Katalin Varjú

Science Director of ELI-HU,

Katalin.Varju@eli-alps.hu regime High-peak- and high-average-power laser development in the few-cycle

\section{Development, characterization and application of high-repetition-rate and} high-power attosecond sources

Studying ultrafast (femtosecond and attosecond scale) dynamics Particle acceleration by ultraintense laser fields, and applications Biomedical effects of pulsed irradiation

Biomedical imaging technologies

Energy research: from solar cells to artificial photosynthesis High-peak-power photonics 


\section{PHYSICAL SCIENCES \& ENGINEERING}

\section{Functional Materials Laboratory (FunMatLab)}

\section{(Uilitner}

Host institution:

Wigner Research Centre for Physics

\section{RI location:}

Budapest, KFKI campus

\section{Status:}

Fully operational, 2012-

\section{Partners:}

Centre for Energy Research

\section{International connections:}

RIs: ESRF, EU-XFEL, SwissFEL, ELIBeamlines

Research organizations: ERC, NRDIO,

Hungarian Academy of Sciences

Available services:

Sample preparation by MBE and chemical methods, sample modification by ion implantation, ion-beam analysis, Mössbauer spectroscopy, X-ray absorption (XANES, EXAFS) and X-ray emission (XES) spectroscopies, fs-time-resolved transient optical absorption spectroscopy, time-resolved fluorescence spectroscopy and stimulated Raman scattering spectroscopy. Neutron reflectometry (available in the frame of collaboration with the Centre for Energy Research).

Website:

https://wigner.hu/nao/en/facilities

Person in charge:

Peter Levai, Director General of

Wigner RCP, levai.peter@wigner.hu

Contact:

Edit Szilágyi, Head of the

Department,

szilagyi.edit@wigner.hu

\section{Description of the research infrastructure}

Predecessors of the Functional Materials Laboratory (FunMatLab) date back to the 1960-ies when materials analysis and engineering with -photons and X-rays, neutrons and accelerated ions at the Central Research Institute for Physics in Budapest started. Subsequently methods, scope and preparation tools were step-by-step extended and organized into a network. FunMatLab is presently an open-access research infrastructure (RI) accessible to all scientists, developers and students worldwide.

Major FunMatLab facilities include a molecular beam epitaxy (MBE) equipment, a chemical technology and isotope laboratory, a heavy-ion implanter, a Van de Graaff accelerator with ion-beam analysis (IBA), a Mössbauer laboratory with spectrometers of various detection methods and sample environments, a polarized-beam neutron reflectometer as well as an X-ray optics development and high-resolution X-ray spectroscopy (XANES, EXAFS, and XES) laboratory, and set-ups for femtosecond-resolved pump-probe laser spectroscopies. These latter include transient optical absorption, time-resolved fluorescence, and stimulated Raman scattering (fs-SRS). The X-ray and laser techniques were developed in the last decade using an ERC grant as well as the national excellence programmes Momentum, VEKOP and NKP.

\section{Activities and services}

Proposals can be submitted any time and will be checked for feasibility first. In case of a positive outcome, financial, cooperation and intellectual property conditions will be negotiated in line with public and transparent rules. FunMatLab encourages accessing the facilities in smart-access mode, i.e. with mail-in samples and, if possible, remote control by the users from their home institutes or universities. FunMatLab offers sample preparation and analytical services that serve as precondition of accessing pan-European RIs like ESRF, ESS and the European XFEL. Most of the analytical methods are non-destructive preserving valuable samples, an important aspect for cultural heritage applications. X-ray and Mössbauer methods have chemical sensitivity, the pump-probe techniques unveil ultrafast molecular dynamics, Mössbauer spectroscopy and neutron reflectometry have magnetic sensitivity, etc. At the heart of materials innovation is an understanding of material structures from the atomic and microscopic scales upwards. Current research topics of groups recently using FunMatLab include studying ultrafast transitions in lightactivated functional molecules, applying $X$-ray spectroscopy as probes with the final aim of developing smart materials of matching structure and function. Very recently, a project used, in a complex way, most of the FunMatLab facilities for fine-tuning magnetic quantum properties to be finally used for developing low-energy devices. In the future. FunMatLab facilities can be efficiently used for research related to various Horizon Europe missions, most notably to Mission 4 (climate-neutral and smart cities) 


\section{PHYSICAL SCIENCES \& ENGINEERING}

\section{Micro- and Nanotechnology Research Laboratory}

Centre for Energy Research
Host institution:

Centre for Energy Research (EK),

Eötvös Loránd Research Network

RI location:

Budapest KFKI Campus

\section{Partners:}

Budapest University of Technology and Economics, Pázmány Péter Catholic University,

Semmelweis University,

Wigner Research Centre for Physics, Institute for Computer Science and Control, 77 Elektronika Ltd., BHE Bonn Hungary Electronics, Semilab Zrt., Diagnosticum Zrt., Knorr-Bremse

\section{International connections:}

Philips Research, Senop, Anton Paar, Z-microsystems, VTT, FRK Osypka, Moscow Nuclear Reasearch University
Available services:

MEMS/NEMS development

2D micropatterns

thin film structures

nanofabrication

\section{Website:}

www.biomems.hu

www.nems.hu

\section{Person in charge:}

Péter Fürjes, PhD - Microsystems

furjes.peter@energia.mta.hu

Contact:

volk.janos@energia.mta.hu
Janos Volk, PhD - Nanosensors

\section{Research Infrastructures}

\section{Description of the}

research infrastructure

The main goal of Micro- and Nanotechnology Research Lab of Centre for Energy Research (Institute of Technical Physics and Materials Science) is to research and develop integrated microsensors, MEMS and BioMEMS systems and nanotechnology based devices (sensors and nanoelectronics)

Major research topics:

Micro- and nanoscale physical, chemical /

biochemical sensors and systems

Micro-and nanoelectromechanical systems (MEMS/NEMS)

Autonomous wireless sensor networks

Microfluidic, nanofluidic, Lab-on-a-Chip and Organ-on-Chip systems

(BioMEMS) and their applications in Point-of-Care diagnostics devices

Implantable microsystems

Optoelectronic devices (IRLED)

Novel functional materials and technologies

Semiconductor nanodevices and quasi-one-dimensional nanostructures, integrated nanosensors

Unique infrastructure in Hungary. The high-tech microtechnology related fabrication and characterisation systems work in a class 10 cleanroom facility. The laboratory is dedicated for 3D processing of 3" and 4" Si / glass / polymer substrates with maximal resolution of $1 \mu \mathrm{m}$, together with lithographic mask manufacturing. Electron beam lithography and focused ion beam (FIB) milling are also available with resolution of $20 \mathrm{~nm}$. The structural design and development are also supported by multi-domain Finite-Element Modelling (FEM), and process simulation. Wide spectra of characterisation techniques are also available: optical (fluorescent) and electron microscopy (SEM and EDS), atomic force microscopy (AFM), profilometry, optical and electrical measurements, electrochemical impedance spectroscopy, microfluidic characterisation, mechanical vibration and climate test chambers, UV / VIS / IR / FTIR spectroscopy, etc.

\section{Activities and services}

The Lab collaborates with several Hungarian scientific centres to perform interdisciplinary research. We are participating in the National Quantum Technology Program (HunQuTech) Besides the scientific projects, the Lab offers technology development services, with industrial partners the higher technology readiness levels are also achievable.

The technological and scientific results are directly transferred into the higher education represented in several lectures, laboratory practices, TDK, diploma and PhD works.

The infrastructure is open for academic and industrial partners to realize complex, purpose-designed microsystems, nanocircuits,

as well as Lab-on-a-Chip devices. 


\section{PHYSICAL SCIENCES \& ENGINEERING}

\section{Aberration corrected transmission electron microscope}

Centre for Energy Research

\section{Host institution:}

Centre for Energy Research (EK), Eötvös Loránd Research Network

\section{RI location:}

Budapest KFKI Campus

Status:

Fully operational, 2018-

\section{Partners:}

Wigner FK,

ELTE, BME, SzTE,

CsFK GGI

Technoorg-Linda Kft

\section{International connections:}

Jülich FRZ, CNR Catania, Linköping

University Sweden, IMR SAS

Kassa, EagleBurgman

Germany,

Website:

www.thinfilms.hu

Person in charge:

\section{Contact:}

Béla Pécz, director

+3613922587

\section{Research Infrastructures}

\section{Description of the research infrastructure}

Centre for Energy Research opened the first aberration corrected transmission electron microscopy laboratory of the country. The special microscope operating at $200 \mathrm{keV}$ provides sub Angström (0.1 nanometer) resolution and opens new possibilities in scientific research and in research and development: in the investigation of semiconductors and ceramics, metals, 2D materials and other nanostructures.

FIB lamella preparation, Arion thinning, TEM and STEM imaging, EDS elemental mapping, structural data and structure models

https://wwww.mfa.kfki.hu/kutatas/

projektek/vekop-themis/

Ákos Horváth, Director General of EK horvath.akos@energia.mta.hu

pecz.bela@energia.mta.hu

\section{Available operation modes:}

$200 \mathrm{kV}$, or $80 \mathrm{kV}$, the latter one for the investigation of beam sensitive

materials

TEM imaging mode at $200 \mathrm{kV}$ with $0.07 \mathrm{~nm}$ resolution

STEM scanning mode with $0.136 \mathrm{~nm}$ resolution

Elemental mapping in STEM mode with 4 EDS detectors built in

$Z$ contrast imaging with STEM HAADF detector

Electron diffraction and orientation maps on polycrystalline materials by

own developed software

Further possibilities on other existing devices of the laboratory:

- $\quad$ FIB (Focussed lon Beam) lamella preparation practically from any material Sample thinning by Ar ions

Analytical electron microscopy with high angle tilting possibility Electron energy los analysis (EELS)

This research infrastructure is operated by the Thin Film Physics Department, which has more than 50 years of experience in transmission electron microscopy.

\section{Activities and services}

The new (Open) laboratory is used in the higher education at the PhD and MSc level. Open for academic partnership, international networking and also for the Hungarian industry. Partnership s offered in the development of electronic components, coatings and functional materials by providing results with short response time at the nanoscale. Could be useful for failure analysis and during the development of the prototypes of new scientific devices. For example the analysis of a coating on a piston ring is possible in the laboratory. 


\section{PHYSICAL SCIENCES \& ENGINEERING}

\section{Machine Vision and Optical Perception Laboratory}

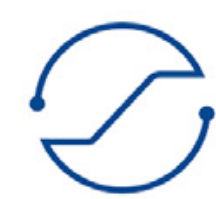

\section{SZTAKI}

\section{Host institution:}

Institute for Computer Science and

Control (SZTAKI), Eötvös Loránd

Research Network

RI location:

Budapest

Status:

Operational

International connections: Khronos Group
Available services:

Real-Time 3D, Virtual Reality,

Mixed Reality

\section{Website:}

//www.sztaki.hu/en/science/

departments/mplab

Person in charge

Tamás Szirányi sziranyi@sztaki.hu

\section{Description of the research infrastructure}

Machine Vision and Optical perception laboratories have a wide range of imaging and display tools:

- Multi-camera motion tracking theatre, Thermal and night vision cameras Hyperspectral cameras, Time of flight cameras

construction scanning

draffic detection, fixed FARO for

- Special Digital Holographic Mircoscope

- Cameras on UAV and UGV drones/robots

ApertusVR: Industrial Virtual Reality laboratory

\section{Activities and services}

High Definition Real-Time 3D Lidars: Velodyne HDL-64E and VLP-16 sensors with $360^{\circ}$ field of view for obstacle detection and navigation for autonomous ground vehicles or UAVs.

Applications are in perception tasks, 3D mobile data collection and 3D mapping solutions. The high precision fixed position FARO lidar is for construction scanning and 3D models for environment analysis; its HDR-camera assigns color and texture information to each 3D point.

Mixed reality smartglass: Microsoft Hololens 2 is a holographic technology, providing an immersive and comfortable mixed reality experience, with precise hand and gaze tracking. ApertusVR: Industrial Virtual Reality Laboratory contains various virtual reality hardware, e.g. the Human-sized Immersive Virtual Reality Display which has been updated in 2016 containing more than ten different types of virtual reality tools. The hardware and the software facility of the ApertusVR were used in the HuNoRob, VisionAir, NeuroCogSpace, and Virtual Learning Factory projects.

Digital Holographic Microscopes: Color, monochromatic, and fluorescent digital holographic microscopes for transparent volumetric water, industrial liquid, or gas inspection are available. Detectibility from 1 micron, recognition from 10 micron. Hyperspectral cameras: 16 band high resolution hyperspectral camera and 4 band multispectral camera with sunshine sensor, both sensitive in the NIR range, used for remote sensing, navigation, smart-farming, conservation of natural habitats and rescue tasks.

Multi-camera motion tracking theatre: the Optitrack system enables the tracking of retroreflective markers with high precision and data rate. 


\section{PHYSICAL SCIENCES \& ENGINEERING}

\section{Nanolab (Electron Microscopy) at the University of Pannonia}

\section{nanolab}

\section{Host institution:}

Research Institute of Biomolecular and Chemical Engineering, University of Pannonia

\section{RI location:}

Veszprém, UP campus

Status:

Fully operational, 2018-

\section{Partners:}

Faculty of Engineering, University of Pannonia

International connections:

RIs: ESTEEM3 (Ernst Ruska-Centre

for Microscopy and Spectroscopy

with Electrons, Jülich; Jožef Stefan

Institute, Ljubljana)

Research organizations:

University of Vienna, University

of Cambridge, University of

Warsaw, CEA Cadarache

Available services:

Scanning transmission electron

microscopy (Thermo Fisher Talos

F200X) with Super-X EDS system

and electron tomography for the

structural, compositional and

morphological analysis of materials

on the nm scale; scanning electron

microscopy (Apreo LoVac) with

EDS and EBSD; sample preparation

for TEM (RMC Powertome

ultramicrotome and Technoorg Linda ion mill)

Website:

https://nanolab.uni-pannon.hu/en/

Person in charge:

Mihály Pósfai, Professor, mihaly. posfai@gmail.com

Contact:

Péter Pekker, lab manager,

pekkerpeter@gmail.com

\section{Research Infrastructures}

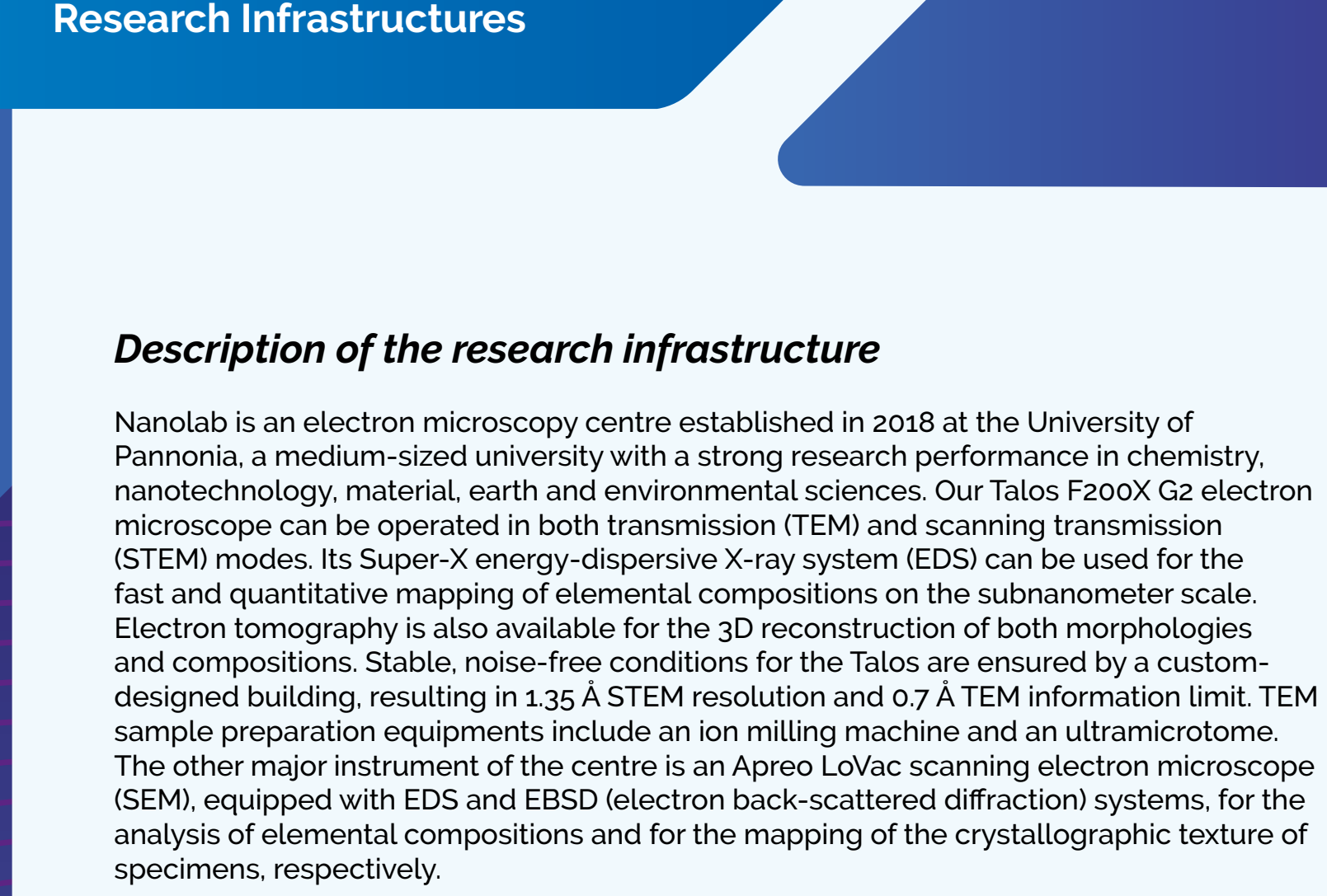

\section{Activities and services}

The electron microscopes are used by both Nanolab staff and external, trained users, both from within and outside of the University of Pannonia. We welcome users from other universities, research institutes and industry as well. Since the installation of the lab we have had a stream of visiting users with a large variety of research programs, both in physical and life sciences (for current projects and conditions of lab use, please see our webpage).

In addition to the service provided to the wider research community and industry, Nanolab staff pursue their own research agenda. Our research interests encompass diverse topics in environmental mineralogy, including the precipitation of carbonate minerals both in natural and artificial systems, the special properties and formation mechanisms of biominerals, the development of biomimetic filamentous magnetic nanostructures, and the characterization of individual atmospheric aerosol particles for understanding their effects on climate and health. 


\section{PHYSICAL SCIENCES \& ENGINEERING}

\section{Atomki Tandetron Laboratory (ATL)}

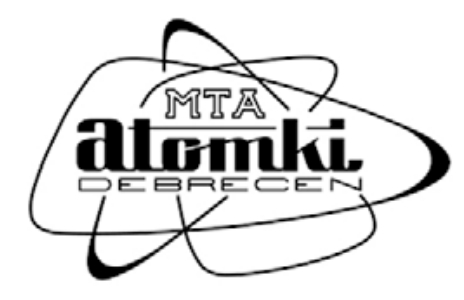

Host institution:

Institute for Nuclear Research (Atomki)

Eötvös Loránd Research Network

\section{RI location:}

Debrecen

Status:

Fully operational, 2018-

\section{Partners:}

DE, Wigner FK, ELTE, MFA, BME

International connections: HZDR, GSI, INFN, CNRS, CERN, University of Surrey, University of Singapore, Jozef Stefan Institute, Ruđer Bošković Institute

RIs and research organizations: RADIATE, EUROPLANET,

IPERION-HS, E-RIHS,
Available services:

Website:

https://wwww.atomki.hu/en/

https://tandetron.atomki.hu/leaflet.

pdf

Person in charge:

Dr. Zsolt Dombrádi, director

director@atomki.hu

\section{Contact:}

Dr. István Rajta

head of the laboratory

rajta@atomki.hu

\section{Open access:}

Services are available in an open access scheme, through the PAC: https://www.atomki.hu/en/pac

\section{Research Infrastructures}

\section{Description of the research infrastructure}

The Atomki Accelerator Centre incorporates several low-energy charged-particle accelerators, which offer the possibility of choosing ions with various charge states, energies and beam intensities.

The Tandetron accelerator was manufactured by High Voltage Engineering Europa B.V. There are three ion sources attached to the accelerator, these are capable of generating high intensity and brightness of proton, helium and various heavy ion beams. On the highenergy end a 90 degree analysing magnet has been deployed, as the result of which high energy stability can be reached. The switcher magnet has 9 exit ports, several different endstations are already built, some are under construction (as of June 2020). Typical beam parameters: $200 \mathrm{keV}-4 \mathrm{MeV}$ protons from nA to $200 \mu \mathrm{A}, 200 \mathrm{keV}-6 \mathrm{MeV}$ helium from nA to $40 \mu \mathrm{A}$, and up to $\sim 10 \mu \mathrm{A}$ of various heavy ions (energy depending on charge state). The project was funded by the infrastructure grants of the Hungarian Academy of Sciences, and the GINOP (Economic Development and Innovation Operational Program) grant: GINOP-2.3.3-15-2016-00005.

\section{Activities and services}

The high-quality ion beams provided by the accelerator can be used in a wide range of research projects both in basic and applied sciences. The former includes, e.g., atomic physics, material science and nuclear astrophysics, while the latter range from medical to atmospheric science and archaeology. In nuclear astrophysics, processes going on in stars and supernovae typically correspond to the energy range available at the Tandetron. In an ice chamber for astrochemistry, ion induced chemical processes are studied above $10 \mathrm{~K}$ temperature in frozen gas mixtures. It serves as a transnational access facility of the EUROPLANET 2024 RI project. For fundamental nuclear physics, an updated setup is installed for extending the investigations of the anomaly observed in the e+e- angular correlation. The installation of a complex ion beam analytical (IBA) endstation allowed for the application of a wide range of ion beam analytical methods. IBA techniques are widely used for the structural and compositional characterization of materials. Additionally, IBA methods can also be applied coupled to a nuclear microprobe, and on the newly developed nanoprobe, which allow lateral imaging of the samples. Both of them can be applied in various IBA tasks and proton beam writing (PBW), which is a 3-dimensional direct write lithography method.

\section{NATIONAL RESEARCH, DEVELOPMENT AND INNOVATION OFFICE} HUNGARY 


\section{PHYSICAL SCIENCES \& ENGINEERING}

\section{ZalaZONE Automotive Proving Ground}

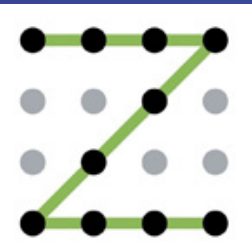

zone

Host institution: Ground

RI location:

Zalaegerszeg, West Hungary

Status:

Partially operational

International connections: AVL Hungary, Ericsson, Furukawa Electric Group, Inventure Automotive, Knorr-Bremse Hungary, Magyar Közút Nonprofit Ltd., MouldTech Ltd., Robert Bosch Ltd., eMobi Ltd.
ZalaZONE Automotive Proving
Research organizations: Austrian Institute of Technology, EU Joint Research Center, Fachhochschule Campus Wien HW Dresden, TU Graz, TU Wie, Linz Center of Mechatronics, Virtual Vehicle, Pannon University, Széchenyi István University,

Bay Zoltán Researchinstitution

\section{Website:}

www.zalazone.hu

Person in charge:

Dr. András Háry managing director apz@apz.hu

\section{Contact:}

Dr. Zsolt Szalay R\&I manager

zsolt.szalay@auto.bme.hu

\section{Description of the research infrastructure}

The aim of the testing grounds is to provide competitive testing and validantion infrastructure the industry, considering the spread of autonomous and electric vehicles as well as newly developing testing requirements. This will be served be the multilevel validation environment addressing the European market and many of its automotive segments.

Vision: Creating a comprehensive testing environment for vehicles and communication technologies of the future, multilevel development testing possibilities ranging from prototype to compledet serial product testing"

\section{Activities and services}

The co-operation of education and education-based researches is a main element of the project. The automotive proving ground has a key importance as a complex and integrated Research \& Development facility which supports customers and experimental developments. The ZalaZONE Research and Technology Centre is located just beside the proving ground, in a very close relation with its activities. It was opened last year and functions as an incubator/accelerator for SMEs and start-ups as well as university based $R \& D$ centre, for Hungarian, regional, European, and global university and industrial partners, where cooperation and collaboration between enterprises and universities are strategically key focus points. The practical dual training program for high school students, where students can acquire the theoretical knowledge, they have received in higher education contributes to the success of the project.

Tests on the interaction of autonomous vehicles and drones may soon begin at the drone testing and development centre to be established next to ZalaZONE in the near future. 


\section{SOCIAL \& CULTURAL INNOVATION}

\section{Atomki Laboratory for Heritage Science (HSLab)}

\section{atrombit: HSLab}

\section{Host institution:}

Institute for Nuclear Research (Atomki),

Eötvös Loránd Research Network

\section{RI location:}

Debrecen

\section{Status:}

Fully operational, 2019-

\section{Partners:}

Atomki Tandetron Laboratory, carbon dating facility, University of Debrecen

International connections:

RIs: E-RIHS

Research organizations: Partner in EU projects (H2O2O): IPERION HS, E-RIHS PP
Available services:

material characterization of art and archaeological objects; other interdisciplinary applications

Website:

https://hslab.atomki.hu

Person in charge:

Zsolt Dombrádi director of Atomk director@atomki.hu

\section{Contact:}

Zita Szikszai, head of laboratory

szikszai.zita@atomki.hu

\section{Description of the research infrastructure}

The Laboratory for Heritage Science was established in 2019 to promote research in the field of cultural and natural heritage in collaboration with national and international partners. The laboratory is based on the decades-long expertise in non-destructive material characterisation using focused ion beams provided by the accelerator facility of the institution. Thanks to an infrastructure development project, an assortment of state-ofthe-art analytical and imaging devices could be procured, which enables more complex examinations in a wide range of scales.

\section{Activities and services}

HSLab conducts ion beam analytical investigations to determine the concentration and distribution of elements both in vacuum and in-air (for larger or sensitive artefacts) with high lateral resolution. The laboratory provides trans-national access to the ion beam analytical facility within the EU H2020 IPERION HS (Integrated Platform for the European Research Infrastructure on Heritage Science) programme, continuing from the former CHARISMA and IPERION CH programmes.

Elemental analysis and mapping is also carried out with a micro-XRF device. Besides more traditional techniques, optical imaging is conducted with a digital 3D microscope which yields quantitative information about the structure of the objects in addition to the excellent image quality. A variable pressure scanning electron microscope (SEM) with analytical modalities is also available. This instrumentation is fitted with a Raman microscope and is able to function as an integrated SEM-Raman microscope. All these techniques are non-destructive and are offered for interdisciplinary research. Projects from national partners (museums, universities, research institutions) are carried out within various frameworks, more recently within the E-RIHS.hu initiative. E-RIHS. hu is the national consortium led by Atomki with the participation of the Centre for Energy Research, the Wigner Research Centre for Physics, and the Hungarian National Museum, representing Hungary in the preparatory phase of the European Infrastructure for Heritage Science (E-RIHS).

$\mathrm{HSLab}$ is also active in higher education and science promotion. 


\section{oo SOCIAL \& CULTURAL INNOVATION}

\section{HunCLARIN}

\section{CLARIN}

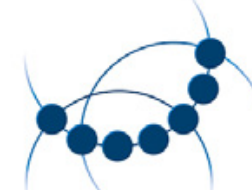

Host institution:

Research Institute for Linguistics

\section{RI location:}

Budapest, Hungary

\section{Status:}

Partially operational

\section{Partners:}

Research Institute for Linguistics (coordinator)

Institute for Computer Science and Control, Hungarian Academy of Sciences

MOKK Centre for Media Research and Education, Budapest University of Technology and Economics

Department of Telecommunications and Media Informatics, Budapest University of Technology and Economics

University of Szeged

University of Debrecen

MorphoLogic Ltd

Pázmány Péter Catholic

University
International connections:

ESFRI CLARIN-ERIC

RIs: 42 RIs (Corpora: 23 Language technology tools: 19)

Available services: http://clarin.hu/

Website:

http://clarin.hu/

\section{Person in charge:}

Tamás Váradi

varadi.tamas@nytud.hu

\section{Description of the} research infrastructure

CLARIN ERIC (Common Language Resources and Technology Infrastructure) is a European network of research infrastructures that makes digital language databases and language processing tools available to researchers in the humanities and social sciences.

HUN-CLARIN, in line with the overall CLARIN mission, considers it a high priority to support humanities and social science research with suitable language technologies and language resources.

The current 8 members of HunCLARIN all represent leading centres of Hungarian language and speech processing. The coordinator is the Research Institute of Linguistics. The language technology resources (eg monolingual, multilingual and thematic corpora) and tools (eg morphological analysts) developed by the partners make it possible, for example, to analyze the content of large corpora (eg from a given historical age), or automatic coding of psychological message contents.

\section{Activities and services}

HUN-CLARIN Roadshows: HUN-CLARIN devised the concept of a Roadshow series that is based on the idea of proactively (and literally) bringing language technology to where humanities research is actually done, namely, to Hungarian universities. The other key concept behind the Roadshows is that instead of a one-sided evangelisation of language technology, the workshop should mobilise and showcase local initiatives (workshops so far: Szeged, Debrecen, Pécs).

Web-service of key Hungarian resources and tools: e-magyar (e-Hungarian) The toolchain was developed in 2016. The rationale for it was based on a clear vision of an open, modular, extendable and easy-to-use pipeline for Hungarian, which was suitable for non-specialists and developers alike.

Corpora: Multimodal HuComTech Corpus, Hungarian Webcorpus, Hungarian National Corpus, 4lang, Hungarian Generative Diachronic Syntax etc.

Language technology tools: Hunalign, Hunmorph, HunToken, MetaMorpho, Hungarian Nooj. Mazsola, magyarlanc etc.

regional, European, and global university and industrial partners, where cooperation and collaboration between enterprises and universities are strategically key focus points. The practical dual training program for high school students, where students can acquire the theoretical knowledge, they have received in higher education contributes to the success of the project.

Tests on the interaction of autonomous vehicles and drones may soon begin at the drone testing and development centre to be established next to ZalaZONE in the near future. 


\section{f DATA, COMPUTING AND Digital RIs}

\section{Hungarian National Supercomputing Service and Competence Centre}

\section{KIFÜ}

Host institution:

Governmental Agency for IT

Development, KIFÜ

RI location:

5 KIFÜ HPC Centres in Hungary

(Budapest, Debrecen, Miskolc, Pécs,

Szeged)

Status:

fully operational in current setup

since 2015 (established in 2003)

\section{Partners:}

about 31 research institutes $(71$

sites); 44 universities (118 sites); 5947

primary and secondary schools; 420

libraries, museums and other public

collections (503 sites).

International connections: RIs: GEANT, PRACE, EOSC, EUROHPC, RDA

RIs: GEANT, PRACE, EOSC, EUROHPC ELI-ALPS

\section{Description of the research infrastructure}

KIFÜ's e-infrastructure for research and education complies with European standards and demands, by featuring a complex portfolio of services, with full connection to the approx. 40 European NRENs (National Research and Education Network e-infrastructures), and indirect connection to an additional approx. 60 non-European NRENs. It covers all internationally accepted functions of ICT-based communication and cooperation, information processing and data storage, by providing all research areas with e-infrastructure.

The e-infrastructure of KIFÜ, as part of the GÉANT infrastructure (the European backbone network connecting the NRENs and supporting the ICT infrastructure for research and education in Europe) and of the PRACE and EUROHPC infrastructure (the pan-European supercomputing infrastructures), provides stable and full-featured connection and cooperation possibilities. It enables access to all research institutions and researchers in Europe, including all major European research infrastructures. Multimedia information management, resource and service virtualisation, federated identification and access management, specific educational and research support service are among the tools built in the system for a better user experience.

\section{Activities and services}

On top of the KIFÜ provided national e-infrastructure (networking,federated identity, cloud and mutloimedia collaboration) services - KIFÜ built a Hungarian Supercomputing Service and Competence Center.

During the 19 years' experience laid down in supercomputing and high volume, distributed data storage the NIIF Program augmented a large piece of distributed scientific infrastructure and corresponding support services. They are broadly used for contemporary scientific simulations and data processing. In these services the whole innovation chain is reinforced, from the high-level algorithmic and software development support to the final exploitation of the scientific data produced.

As of 2020, KIFU offers computational services to thousands of domestic users through the HPC excellence centre. The over 448 Tflops ( 8900 CPU+GPU cores) capacity and 8 PB hard drive storage, accessible to researchers in the country and in the region will be extended in the next year to about 5 PFlops computational capacity, available to the entire domestic research community.

The national HPC Competence Centre operated by KIFU is providing high level technical support for the users for efficient usage of the HPC tools and services, as well as it aims to spread the HPC knowledge in the community by organizing trainings, education and events. It is also going to foster the cooperation between industrial partners and academia and it is actively seeking the ways for the usage of HPC in development and innovation 


\section{A DATA, COMPUTING AND Digital RIs}

\section{Internet of turing Things (loLT)}

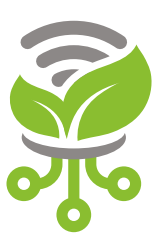

\section{INTERNET OF LIVING THINGS}

\section{Host institution:}

Department of Software Engineering, University of Szeged

\section{RI location:}

Dugonics tér 13, 6720 Szeged, Hungary

\section{Status:}

Fully operational, 2015

\section{Partners:}

Biological Research Centre, Eötvös Group on Artificial Intelligence

International connections: Samsung, ARM, Intel Nokia, EQALM
Available services:

Open source software development JerryScript adaptation, domain adaptation. Static code analysis. loT-Fog-Cloud simulation. Analysis of medical texts and images development.

\section{Website:}

https://www.sed.inf.u-szeged.hu/iolt

\section{Person in charge:}

Tibor Gyimóthy, head of research Rudolf Ferenc, head of department

\section{Contact:}

Tibor Gyimóthy

gyimothy@inf.u-szeged.hu
(Al). Telemedicine application Loránd Research Network; Research

\section{Description of the research infrastructure}

Open source IoLT software platform that allows even non-IT researchers to develop biological, medical, and also conventional loT applications. The platform enables researchers of any discipline to develop and execute loT applications by providing easy-to-use programming interfaces and tool sets. The platform supports a wide range of devices in general, and ultra-low-resource, ultra-cheap loT devices in particular. Available components: JavaScript interpreter developed for heavily constrained loT devices (JerryScript); loT development environment for rapid application development; tools for software quality assurance including static code analysis, source code quality and vulnerability checks; device drivers, communications, loT cloud infrastructure and simulators; algorithms for ensuring data safety and security.

\section{Activities and services}

Development of the platform is continuous, which includes the adaptation of the core JerryScript execution environment to application-specific peripherals. The development of loLT applications is facilitated through the high-level programming of ultra-low-resource sensors for adaptive data collection and processing. Simulation tools are developed for investigating the efficient and secure management of loT applications in fog and cloud systems. Advanced Al tools are available, e.g., for medical applications and natural language processing

The platform enables the assessment of the impact of environmental factors determining the growth and stress reactions on individual plants. In medical practice it supports actigraphic research for identifying new ultradian and slower periodic and stochastic components in human physical activity patterns and establishing their correlation to physical conditions, activities, and certain psychiatric disorders. Devices running the platform can greatly increase the effectiveness of work on cell cultures by facilitating the testing of potential active substances. To increase the efficiency of personalised therapies, the platform can aid the analysis of microscopic images and automatic classification The Inclouded services provided on the top of the loLT platform support the whole value chain of the clinical trials, including study design, ISO 13845 certified telemedicine environment with integrated sensors, workflows, big data processing, and evaluation.

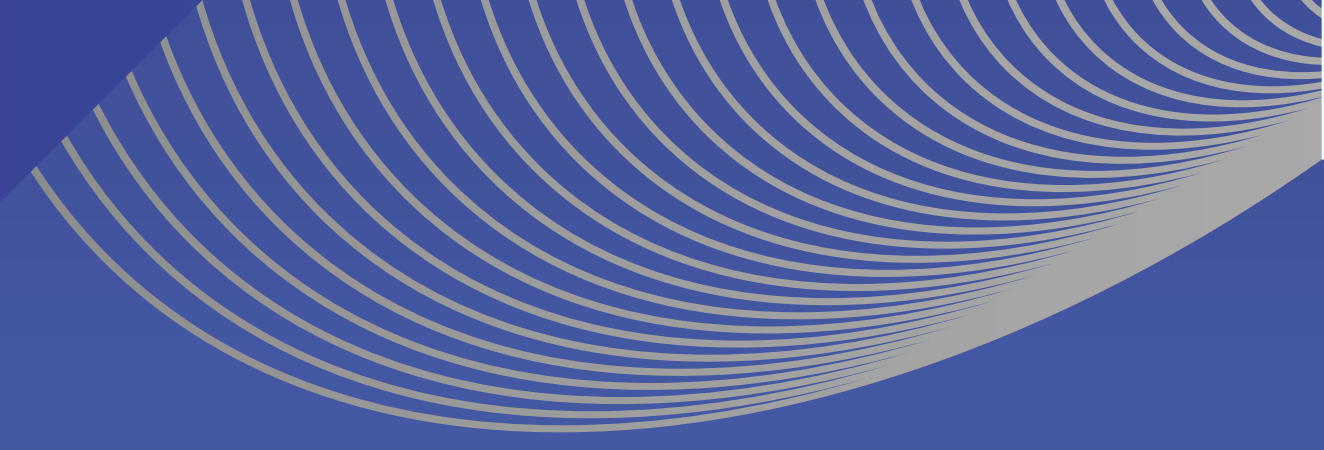

NATIONAL RESEARCH, DEVELOPMENT AND INNOVATION OFFICE 


\section{A DATA, COMPUTING AND Digital RIs}

\section{Wigner Datacenter}

\section{Uî̉ener}

Host institution:

Wigner Research Centre for Physics

\section{RI location:}

Budapest, KFKI campus

Status:

Fully operational, 2012-

Partners:

Ministry of Innovation and Technology (ITM), National Research Development and Innovation Office

(NKFIH), Eötvös Loránd Research

Network (ELKH), KIFÜ, HRDA,

Institute for Computer Science and Control (SZTAKI)

International connections: CERN, ELI, EGO VIRGO, GEANT, EOSC, RDA

RIs: ELI-ALPS

Research organizations:

Liverpool John Moores

University
Available services:

Missions in data science with a wide scope, ELKH Cloud, Wigner Cloud GPU Days, HEPTECH AIME

\section{Website:}

https://wignerdc.wigner.hu/ https:// gpu.wigner.mta.hu/en/ https://gpuday.hu/

Person in charge:

Peter Levai, Director General of

Wigner RCP, levai.peter@wigner.hu

\section{Contact:}

Jozsef Kadlecsik, Head of the Wigner Datacenter, kadlecsik.jozsef@wigner. hu

Gergely G. Barnaföldi, Wigner GPU Laboratory, barnafoldi.gergely@ wigner.hu

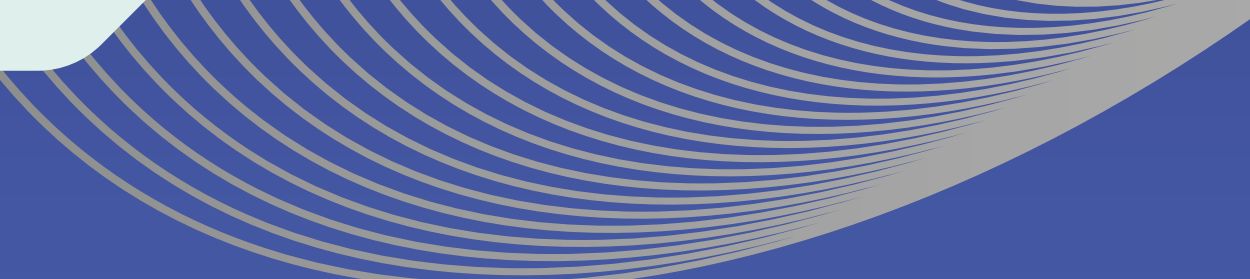

\section{Description of the research infrastructure}

The Wigner Datacenter is one of the most modern information technology (IT) infrastructure in Hungary and in Central Europe. At the same time it is one of the leading IT infrastructures supporting research activities. The Datacenter was built in 2012 with the support of the Ministry of National Development; a project fitting into Europe's Digital Agenda and the Digital Renewal Action Plan. It started to work in 2013 as the CERN's additional Tier-o computer centre with $4 \mathrm{MW}$ capacity. The original CERN project finished at the end of 2019, however part of the existing infrastructure has been reorganized into the ALICE Analysing Facility, which is under development now. In parallel with the CERN project, the Wigner DC started to develop the Wigner Cloud (2015) and the ELKH Cloud (2016), which was named earlier as MTA Cloud. These cloud services offer a high quality IT support to national and regional research projects, for example the National Brain Program and the National Quantum Technology Program. Wigner Cloud supports further international research projects like ELI, Virgo, and several $\mathrm{H} 2020$ projects. The twin modul of the ELKH Cloud can be found at the Institute for Computer Science and Control (SZTAKI) The main users of the clouds are researchers from particle physics, gravitation research, artificial and intelligent materials, brain research, bioinformatics, and computational sciences. These areas involve around 800 potential users. During last 3 years more than 100 projects had been accomplished on the clouds.

\section{Activities and services}

The ELKH Cloud and Wigner Cloud together give 1368 virtual CPU core, 527 TB disc space and 1.6 PB capacity of tape unit for the service of the Hungarian and regional research projects. In 2018 Wigner Datacenter extended the Cloud service with GPU units, which are 8 NVIDIA Tesla V100 unit with capacity 62 Teraflop (double precision) and 1 Petaflop (for tensor calculations). For middle of 2021 these capacities will be tripled by a new development plan, which is under completion.

In parallel, locally a CERN TIER-2 station runs with 1000 CPU-core (2000 virtual core, 15000 HSO6) and 1 PB storage unit. Furthermore, the Wigner GPU Laboratory offers opportunity to run special programs, to discuss massive-parallel computing problems and helps to start coding/programming activities in educational, industrial and research topics. Workshops and focused trainings are organized regularly, building the bridge between state-of-the art IT technologies, programmers, and researchers of many fields. Furthermore, the local GPU Laboratory offers opportunity to run special programs, to discuss GPU-related problems and helps to start GPU-based activities in educational, industrial and research topics. Workshops and focused trainings are organized regularly.

NATIONAL RESEARCH, DEVELOPMENT AND INNOVATION OFFICE HUNGARY 
